Published in final edited form as:

Cell Tissue Res. 2016 March ; 363(3): 693-712. doi:10.1007/s00441-015-2316-3.

\title{
Impact of Chromogranin A deficiency on catecholamine storage, catecholamine granule morphology and chromaffin cell energy metabolism in vivo
}

\author{
Teresa Pasqua ${ }^{1}$, Sumana Mahata ${ }^{2}$, Gautam K. Bandyopadhyay ${ }^{1}$, Angshuman Biswas ${ }^{1}$, Guy \\ A. Perkins ${ }^{3}$, Amiya P. Sinha-Hikim ${ }^{4,5}$, David S. Goldstein ${ }^{6}$, Lee E. Eiden ${ }^{7}$, and Sushil K. \\ Mahata ${ }^{1,8,9}$ \\ ${ }^{1}$ Department of Medicine, University of California - San Diego, San Diego, CA, USA \\ ${ }^{2}$ California Institute of Technology, Pasadena, CA, USA \\ ${ }^{3}$ National Center for Microscopy and Imaging Research, San Diego, CA, USA \\ ${ }^{4}$ Charles Drew University of Medicine and Science, Los Angeles, CA, USA \\ ${ }^{5}$ David Geffen School of Medicine, University of California-Los Angeles, Los Angeles, CA, USA \\ ${ }^{6}$ Clinical Neurocardiology Section, NINDS-IRP, Bethesda, MD, USA \\ ${ }^{7}$ Section on Molecular Neuroscience, NIMH-IRP, Bethesda, MD, USA \\ 8VA San Diego Healthcare System, San Diego, CA, USA \\ ${ }^{9}$ Metabolic Physiology \& Ultrastructural Biology Laboratory, Department of Medicine, University of \\ California at San Diego, 9500 Gilman Drive, La Jolla, CA 92093-0732, USA
}

\begin{abstract}
Chromogranin $\mathrm{A}(\mathrm{CgA})$ is a prohormone and granulogenic factor in neuroendocrine tissues with a regulated secretory pathway. The impact of $\mathrm{CgA}$ depletion on secretory granule formation has been previously demonstrated in cell culture. However, studies linking the structural effects of $\mathrm{CgA}$ deficiency with secretory performance and cell metabolism in the adrenomedullary chromaffin cells in vivo have not previously been reported. Adrenomedullary content of the secreted adrenal catecholamines norepinephrine (NE) and epinephrine (EPI) was decreased 30$40 \%$ in Chga-KO mice. Quantification of NE and EPI-storing dense core (DC) vesicles (DCV) revealed decreased DCV numbers in chromaffin cells in Chga-KO mice. For both cell types, the DCV diameter in Chga-KO mice was less (100-200 nm) than in WT mice (200-350 nm). The volume density of the vesicle and vesicle number was also lower in Chga-KO mice. Chga-KO mice showed an $\sim 47 \%$ increase in DCV/DC ratio, implying vesicle swelling due to increased osmotically active free catecholamines. Upon challenge with $2 \mathrm{U} / \mathrm{kg}$ insulin, there was a diminution in adrenomedullary EPI, no change in NE and a very large increase in the EPI and NE
\end{abstract}

Correspondence to: Sushil K. Mahata.

Teresa Pasqua and Sumana Mahata contributed equally to this work.

Conflict of interest

The authors have nothing to declare. 
precursor dopamine (DA), consistent with increased catecholamine biosynthesis during prolonged secretion. We found dilated mitochondrial cristae, endoplasmic reticulum and Golgi complex, as well as increased synaptic mitochondria, synaptic vesicles and glycogen granules in Chga-KO mice compared to WT mice, suggesting that decreased granulogenesis and catecholamine storage in CgA-deficient mouse adrenal medulla is compensated by increased VMAT-dependent catecholamine update into storage vesicles, at the expense of enhanced energy expenditure by the chromaffin cell.

\section{Keywords}

Norepinephrine; Epinephrine; Dense core vesicle; Synaptic vesicle; Mitochondria

\section{Introduction}

Chromogranin $\mathrm{A}(\mathrm{CgA})$, the index member of the chromogranin/secretogranin protein family, is co-stored and co-released with catecholamines from dense core (DC) vesicles (DCV) in the adrenal medulla and the post-ganglionic sympathetic axons (Bartolomucci et al. 2011; Winkler and Fischer-Colbrie 1992). The extracellular function of $\mathrm{CgA}$ includes the generation of bioactive peptides, such as the insulin-regulatory hormone pancreastatin (Bandyopadhyay et al. 2015; Gayen et al. 2009b; Sanchez-Margalet et al. 2010; Tatemoto et al. 1986), the vasodilating and cardioprotective vasostatin (Aardal et al. 1993; Tota et al. 2008), the anti-adrenergic (Mahata et al. 2003; Mahata, et al. 2010; Mahata et al. 1997), anti-hypertensive (Mahapatra et al. 2005), anti-obesity (Bandyopadhyay et al. 2012), proangiogenic (Theurl et al. 2010) and cardioprotective catestatin (Angelone et al. 2008; Mahata et al. 2010) and the pro-adrenergic serpinin (Tota et al. 2012). The intracellular function of $\mathrm{CgA}$ includes the initiation and regulation of DCV biogenesis and sequestration of hormones in neuroendocrine cells (Elias et al. 2012; Iacangelo and Eiden 1995; Kim et al. 2001; Taupenot et al. 2002).

We have previously shown that Chga-deficient (Chga-KO) mice in mixed genetic background (50 \% 129SvJ and $50 \%$ C57BL/6) are hyperadrenergic and hypertensive (Mahapatra et al. 2005) and display diminished baroreflex sensitivity (Gayen et al. 2009a) and heart rate variability (Dev et al. 2010). It seems paradoxical that $\mathrm{CgA}$ deficiency is associated with dysregulated but apparently increased, catecholamine secretion, while studies in cellula (Elias et al. 2012; Kim et al. 2001) suggest a role for CgA in the production of catecholamine-containing secretory vesicles. We wish to attempt to resolve this paradox by careful examination of the morphological status of catecholamine secretory vesicles, catecholamine content, catecholamine biosynthesis and metabolic status of adrenomedullary chromaffin cells in congenic CgA-deficient and wild-type (WT) mice.

The term "vesicular cocktail" was coined by Winkler and colleagues (Winkler and FischerColbrie 1992; Winkler et al. 1987) to indicate the composition of the chromaffin granules inside the DCV. This cocktail includes high concentrations of catecholamines $(0.5-1 \mathrm{M})$, ATP $(\sim 150 \mathrm{mM}), \mathrm{Ca}^{2+}(\sim 40 \mathrm{mM})$ and $\mathrm{CgA}(\sim 1.8 \mathrm{mM})$ (Winkler and Westhead 1980). CgA binds to both catecholamines and $\mathrm{Ca}^{2+}$ (Videen et al. 1992). CgA binds catecholamines with 
low affinity $\left(\mathrm{K}_{\mathrm{d}}=2.1 \times 10^{-3} \mathrm{M}\right)$ but high capacity (32 mol catecholamines $/ \mathrm{mol} \mathrm{CgA}$ ) (Videen et al. 1992) allowing it to form a binding complex within the vesicle (Berneis et al. 1973; Kopell and Westhead 1982; Mahapatra et al. 2004; Yoo and Albanesi 1991). A theoretical osmolarity of $1500 \mathrm{mOsm}$ has been calculated for the internal volume of the DCV, from the concentrations of its constituents if these were not bound in an osmotically inert form (Borges et al. 2010). By reducing the number of free molecules and ions within the solution, the binding of $\mathrm{CgA}$ with catecholamines and $\mathrm{Ca}^{2+}$ provides a mechanism for reducing this theoretical intravesicular osmotic pressure, incompatible with vesicle integrity given its water permeability and facilitating the storage of high concentrations of the transmitter within the small volume of the vesicle (Haigh et al. 1989; Kopell and Westhead 1982). In addition, storage of catecholamines in an osmotically inert form, mobilized by solubilization upon exocytotic release, significantly reduces the energy burden of continuous leakage and re-uptake of catecholamines across the vesicular membrane (Henry et al. 1994; Johnson 1988; Schuldiner 1994). Thus, a lack of CgA would be expected to increase the osmotic pressure and decrease the storage capacity for catecholamines, as well as increasing the energy requirement for maintenance of a sufficient concentration of catecholamines, via vesicular transporter action, for quantal release during exocytosis.

This expectation has been borne out in neuroendocrine cell lines in which $\mathrm{CgA}$ has been knocked down and in chromaffin cells obtained from WTand CgA knockout (Chga-KO) mice. For example, $\mathrm{PC} 12$ cells lacking $\mathrm{CgA}$ expression exhibit decreased vesicle numbers and dysregulated shape and size of the vesicles, compared to WT cells (Kim et al. 2001). More appositely, chromaffin cells from Chga-KO mice showed $\sim 30 \%$ reduction in both catecholamine content and catecholamine release, upon depolarization, compared to those from WT mice (Montesinos et al. 2008). However, no reports yet exist that quantitatively and qualitatively link $\mathrm{CgA}$ deficiency in vivo to the appearance and storage capacity of chromaffin granules in chromaffin cells in situ, with the exception of a single report in which quantitative analysis of vesicle and granule morphology was not conducted, perhaps due to the lack of congenic controls for the CgA-deficient mice examined (Hendy et al. 2006). Here, we provide ultrastructural stereological evidence demonstrating that a lack of $\mathrm{CgA}$ causes specific changes in secretory granules that are consistent with observations obtained ex vivo and in cell culture, indicative of increased osmotically active free catecholamines as a function of CgA deficiency (Colliver et al. 2000; Gong et al. 2003). In addition, we examined the effects of $\mathrm{CgA}$ deficiency in vivo on catecholamine content in both quiescent and hypoglycemic mice and correlated these findings with altered adrenomedullary metabolism in Chga-KO mice suggestive of an enhanced metabolic burden associated with catecholamine storage/secretion in the absence of $\mathrm{CgA}$ and consistent with the hypertensive and hyperadrenergic phenotypes reported previously in Chga-KO mice (Gayen et al. 2010; Mahapatra et al. 2005).

\section{Materials and methods}

\section{Animals}

Chga-KO mice on a stable mixed genetic background (50 \% 129svJ; $50 \%$ C57BL/6 J) were backcrossed to C57BL/6 J mice for 7 generations to obtain Chga-KO mice with a C57BL/6 J 
background. Male WT and Chga-KO C57BL/6 mice (1-12 months in weight gain studies; 6 months old in all other experiments reported here) were studied. Mice were kept on a 12-h dark/light cycle and fed ad libitum with a normal chow diet (NCD: $14 \%$ calories from fat; LabDiet 5P00). Institutional Animal Care and Utilization Committees from The University of California San Diego and the NIMH-IRP approved all procedures performed at each institution.

\section{Measurement of adrenomedullary catecholamines}

To extract catecholamines from the adrenal gland, $0.3 \mathrm{ml}$ of ice-cold $0.4 \mathrm{~N}$ perchloric acid was added to the tissue. Following homogenization and centrifugation $(8000 \mathrm{rpm}, 15 \mathrm{~min}$ at $4{ }^{\circ} \mathrm{C}$ ) the supernatant was removed. An internal standard 3,4-dihydroxybenzylamine (DHBA: $20 \mathrm{ng}$ ) and an antioxidant sodium meta-bisulfite were added to the supernatant to make final concentrations of $0.125 \mathrm{mM}$. Alumina ( $40 \mathrm{mg}$, aluminium oxide, activity grade; Super I, type WA-4; Sigma-Adrich, Allentown, PA, USA) was added to the samples and the $\mathrm{pH}$ of the solution was raised to 8.6 by adding Tris buffer [0.96 M Tris, $50 \mathrm{mM}$ EDTA (pH 8.69)]. After a 30-min incubation and centrifugation ( $5000 \mathrm{rpm}, 5 \mathrm{~min}$ at room temperature), the supernatant was discarded and the beads were washed with water. Catecholamines were eluted with $0.4 \mathrm{ml}$ of a solution of $0.1 \mathrm{~N} \mathrm{HCl} / 0.1 \mathrm{mM}$ sodium meta-bisulfite. Catecholamine assay was done by using high-pressure liquid chromatography (HPLC) coupled to an electrochemical detector (Waters 600E Multisolvent Delivery system and Waters 2465 Electrochemical Detector; Milford, MA, USA). Separation was performed on an Atlantis $\mathrm{dC} 18$ column $(2.1 \times 150 \mathrm{~mm}, 3 \mu \mathrm{m})$ from Waters. The mobile phase $(0.15 \mathrm{ml} / \mathrm{min})$ was a mixture composed of phosphate-citrate buffer $\left(2 \mathrm{mM} \mathrm{NaH}_{2} \mathrm{PO} 4,268 \mu \mathrm{M} \mathrm{Na} 2 \mathrm{EDTA}, 50 \mathrm{mM}\right.$ sodium citrate, $10 \mathrm{mM}$ diethylamine hydrochloride, $0.072 \%$ 1-octanesulfonic acid, $(\mathrm{pH}$ is adjusted to $\mathrm{pH} 3.1$ using phosphoric acid), $2.2 \% \mathrm{~N}$, N-dimethylacetamide)/acetonitrile at 95:5 (v/v). The data were analyzed using Empower software (Waters) and catecholamine levels (ng/ $\mathrm{\mu g}$ protein or $\mathrm{ng} / \mathrm{mg}$ adrenal) were calculated by comparing with standards and normalized according to the recovery of internal standard.

\section{Hypoglycemic stress and measurement of adrenal catecholamines}

Hypoglycemic stress was carried out as described by Hamelink et al. (2002). Briefly, Humulin R (U-100; Lilly; obtained from NIH Pharmacy) diluted in $0.9 \%$ saline to 0.25 $\mathrm{U} / \mathrm{ml}$, or saline alone, was administered i.p. in a volume of $8 \mu \mathrm{l} / \mathrm{g}$ body weight, to achieve a dose of $2 \mathrm{U} / \mathrm{kg}$. Mice were sacrificed in pairs (saline; insulin) $3 \pm 0.25 \mathrm{~h}$ after injection. There were 18 male and 14 female mice (9 each WT and KO of males; 7 each WT and KO of females). Animals were weighed and handled (sham i.p.-injected; for stress desensitization) the night before and food removed at 1630 hours. The next day, mice were again weighed and handled in the morning and sham and insulin injection carried out at midday (i.e., about 1300 hours of 0600-1800-0600 hours lights on-lights off-lights on cycle). Mice were sacrificed by $\mathrm{CO}_{2}$ inhalation, adrenal glands quickly dissected and frozen on dry ice and catecholamine measurement carried out after tissue disruption in perchlorate and clarification by centrifugation as described (Pacak et al. 1998). 


\section{Light and Transmission Electron Microscopy (TEM)}

Mice were deeply anesthetized and the adrenal glands were perfusion fixed through the left ventricle. Mice were flushed with a pre-warmed $\left(37^{\circ} \mathrm{C}\right)$ calcium and magnesium free buffer, which is composed of DPBS (Life Technologies, Carlsbad, CA, USA), 10 mM HEPES, 0.2 mM EGTA, $0.2 \%$ bovine serum albumin, $5 \mathrm{mM}$ glucose and $10 \mathrm{mM} \mathrm{KCl}$ (flush buffer osmolarity $=354.34 \mathrm{mOsmol} / \mathrm{l}$ ) for $2 \mathrm{~min}$ followed by perfusion with freshly prepared prewarmed $\left(37{ }^{\circ} \mathrm{C}\right)$ fixative containing $2.5 \%$ glutaraldehyde, $2 \%$ paraformaldehyde in $0.15 \mathrm{M}$ cacodylate buffer (fixative osmolarity $=1,350 \mathrm{mOsmol} / \mathrm{l}$ ) for $3 \mathrm{~min}$ using a peristaltic pump (Langer Instruments, Boonton, NJ, USA) set at $40 \mathrm{rpm}$. Adrenal glands were dissected out and put in the same fixative overnight $\left(2 \mathrm{~h}\right.$ at room temperature and $12 \mathrm{~h}$ at $\left.4{ }^{\circ} \mathrm{C}\right)$ and postfixed in $1 \% \mathrm{OsO}_{4}$ in $0.1 \mathrm{M}$ cacodylate buffer for $1 \mathrm{~h}$ on ice. The tissues were stained en bloc with 2-3\% uranyl acetate for $1 \mathrm{~h}$ on ice. The tissues were dehydrated in graded series of ethanol (20-100\%) on ice followed by one wash with $100 \%$ ethanol and two washes with acetone (15 min each) and embedded with Durcupan. Sections were cut at 50-60 nm on a Leica UCT ultramicrotome and picked up on Formvar and carbon-coated copper grids. Sections were stained with $2 \%$ uranyl acetate for 5 min and Sato's lead stain for $1 \mathrm{~min}$. Grids were viewed using a JEOL 1200EX II (JEOL, Peabody, MA, USA) TEM and photographed using a Gatan digital camera (Gatan, Pleasanton, CA, USA). Toluidine blue stained semi-thin $(1 \mu \mathrm{m})$ sections were photographed using an Axio Observer Stand Mot microscope (Carl Zeiss Microscopy, Thornwood, NY, USA). Micrographs were randomly taken from 3 adrenal glands each from WT and Chga-KO mice, which were fixed and processed in two different days.

\section{Morphometric analysis}

To minimize the bias measurements, samples were blinded and 3 people did measurements randomly from different cells (Plattner et al. 1997). Each dense core vesicle (DCV) has an interior dense core (DC) and a halo (empty space between the DC and the vesicle membrane), which are easily visualized using EM. To determine changes in size of the DCV and its DC in samples from Chga-KO and WT adrenal gland, the DCV (core plus halo) and DC diameters were measured using ImageJ $(\mathrm{NIH})$. The line segment tool in ImageJ was used to measure diameters (DCV, DC and SV), length (mitochondria) and lumen width (ER and Golgi). The free-hand tool was used to manually trace around the vesicle membrane (DCV, DC and SV), core (DC) area and cytoplasm area. For determination of the volume density (\%) of vesicles, the sum of the area of the vesicles was divided by the area of the cytoplasm and multiplied by 100 .

Mitochondrial lengths, number per area, volume fractions and cristae volume densities were measured on the tissue images as described previously (Guo et al. 2013). Counting the total number of mitochondria in a given TEM image and dividing by the cytoplasmic area measured in that image determined the number of mitochondria per area. To determine the cristae volume density, the freehand tool in ImageJ was used to manually trace around the mitochondrial outer membrane. The area of the mitochondrion was then calculated using ImageJ. The area of each crista membrane was also calculated in the same manner. The sum of the areas of the total complement of cristae was then divided by the sum of the mitochondrial area to provide the cristae volume density. Mitochondrial fraction (volume 
density) was measured using stereology performed with the aid of Adobe Photoshop (San Jose, CA, USA). Point counting was used to determine the mitochondrial volume densities by overlaying a grid on each digitized image. Mitochondria and cytoplasm lying under intercepts were counted. The relative volume of mitochondria was expressed as the ratio of intercepts coinciding with this organelle to the intercepts coinciding with cytoplasm and reported as a percentage.

\section{In vivo tissue glucose uptake and metabolism}

In vivo glucose uptake and production of glucose-6-phosphate (G6P) was carried out following a published protocol (Crosson et al. 2003) but using double isotopes ${ }^{3} \mathrm{H}$-glucose and ${ }^{14} \mathrm{C}$-2-deoxyglucose (2DG). A cocktail of radiolabeled glucose and $2 \mathrm{DG}$ was combined and injected intraperitoneally ( $1 \mu \mathrm{g} / \mathrm{g}$ body weight, $10 \mu \mathrm{Ci}{ }^{3} \mathrm{H}$-glucose and $1 \mu \mathrm{Ci}{ }^{14} \mathrm{C}-2 \mathrm{DG}$ per mouse) into each overnight-fasted mouse. Blood (5 $\mu$ ) was collected (in $100 \mu \mathrm{l} 1 \mathrm{M}$ perchloric acid) from the tail tip at 0 and $90 \mathrm{~min}$. Blood glucose concentration and radioactivity in blood were determined to calculate specific activity. Mice were euthanized and tissues were excised rapidly and frozen immediately in liquid nitrogen. To determine tissue accumulation of sugar and sugar-phosphates, tissues were homogenized in distilled water (saving an aliquot at $-20{ }^{\circ} \mathrm{C}$ for subsequent protein assay) and deproteinized with $7 \%$ perchloric acid. The samples were centrifuged. The pellets were saved for determination of glycogen content and the supernatants were neutralized with $\mathrm{KHCO}_{3}$. One-half of the volume of each supernatant was counted for radioactivity directly and the other half was mixed with $100 \mathrm{mg} \mathrm{Ag-501 \times 8} \mathrm{mixed} \mathrm{bed} \mathrm{resin,} \mathrm{to} \mathrm{which} \mathrm{distilled} \mathrm{water} \mathrm{was} \mathrm{added,} \mathrm{vortexed}$ three times and then centrifuged (or passed through an AG 1-X8 resin anion exchange column; Bio-Rad Laboratories, Hercules, CA, USA). The radioactivity of free glucose in the supernatant was determined with a beta counter. The difference between total radioactivity (before resin treatment) and supernatant (after resin treatment) radioactivity corresponds to accumulated G6P and 2-DG-6-phosphate (2DG6P). A similar experiment with ${ }^{14} \mathrm{C}$-mannitol was carried out to determine the level of unincorporated radioactivity in the interstitial space. The radioactivity for mannitol incorporation was subtracted from the corresponding glucose values.

\section{Western blotting}

Adrenal glands were homogenized in a buffer containing phosphatase and protease inhibitors as described previously (Bandyopadhyay et al. 2012). Homogenates were subjected to SDS-PAGE and immunoblotted with a $\mathrm{CgA}$ antibody (human $\mathrm{CgA}_{352-372}$ ).

\section{Data presentation and statistical analysis}

Data are expressed as mean \pm SEM. Statistical analyses were performed using Student's $t$ tests as well as one-way ANOVA followed by Dunnett's post hoc test when appropriate. Statistical significance was defined as $p<0.05$. 


\section{Results}

\section{Decreased volume density and number of chromaffin (NE and E) vesicles in Chga-KO mice}

Western blot with $\mathrm{CgA}$ antibody (human $\mathrm{CgA}_{352-372}$ ) demonstrates that $\mathrm{CgA}$ is indeed totally absent from the adrenal glands of Chga-KO mice (Fig. 1a). This antibody detected $\mathrm{CgA}$ at $\sim 75 \mathrm{kDa}$ in WT mice (Fig. 1a). Body weights of WT and Chga-KO male mice were comparable during development and in late adulthood; however, Chga-KO mice appeared to gain weight somewhat more rapidly than their WT counterparts in early adolescence and late adulthood (Fig. 1b). We used 24 -week-old adult male mice, of comparable body weights, for our studies. In toluidine blue-stained semi-thin sections, most of the secretory granules of E cells were stained metachromatically pale purple blue, whereas those of NE cells were stained dark blue (marked by dashed black boundary) in WT (Fig. 1c) and Chga-KO (Fig. 1d) mice. We used a mixture of freshly prepared glutaraldehyde and paraformaldehyde fixative followed by post-fixation with osmium tetroxide to clearly distinguish NE and EPI cells. The preponderance of EPI compared to NE cells was similar in WT and Chga-KO mice. The NE-storing vesicles were osmiophilic and characterized by typical intensely electron-dense granules, some of which have a flattened or tubular appearance (Fig. 1e, f). To our knowledge, ultrastructural figures on DCV in mouse NE cells are not available in the literature. However, flattened DCV of the kind visible in Fig. 1e can be seen in previous literature in rats (Coupland and Hopwood 1966; Patzak and Winkler 1986). In contrast, the EPI-storing vesicles were moderately electron dense and smaller in size (Fig. 1e, f).

Compared to WT mice, both the vesicular volume density (\%) (Fig. 1g) and the number of vesicles per $\mu \mathrm{m}^{2}$ (Fig. 1h) were significantly lower in Chga-KO compared to WT mice.

\section{Decreased catecholamines in the adrenal gland of Chga-KO mice}

The adrenal gland weight was comparable between WT and Chga-KO mice (Fig. 1i). In the adrenal gland of WT mice, EPI $(5.83 \pm 0.52 \mathrm{ng} / \mu \mathrm{g}$ protein $)$ and NE $(3.19 \pm 0.36 \mathrm{ng} / \mu \mathrm{g}$ protein $)$ accounted for 62.8 and $34.4 \%$ of total catecholamines, respectively. In Chga-KO mice, total contents of EPI ( $3.35 \pm 0.29 \mathrm{ng} / \mu \mathrm{g}$ protein) were reduced by $42.5 \%$ and total NE $(2.14 \pm 0.31$ $\mathrm{ng} / \mu \mathrm{g}$ protein) contents were reduced by $32.9 \%$ (Fig. 1j).

\section{NE-storing vesicles in Chga-KO mice exhibit reduced area and diameter}

In WT mice, the NE dense core vesicles (DCV) displayed a dense core (DC; shown by an asterisk in Fig. 2a) and a tiny halo (Fig. 2b; shown by black arrow). In Chga-KO mice, there were three kinds of vesicles: (1) DC and a tiny halo (DCV), (2) decreased DC and swelled halo (SDCV, shown by black arrow in Fig. 2c) and (3) swelled halo with no noticeable DC (SEV) (Fig. 2c, d). In NE cells, we found a $\sim 24 \%$ decrease in the DCV area (Fig. 2e) in Chga-KO (22.9 $\left.\pm 0.57 \mu \mathrm{m}^{2}\right)$ mice compared to WT $\left(17.47 \pm 0.55 \mu \mathrm{m}^{2}\right)$ mice (Fig. $2 \mathrm{a}-\mathrm{d}$ ). Chga-KO mice had an even more profound decrease (by $62.9 \%$ ) in the DC area (Fig. 2e; WT: $15.02 \pm 0.42 \mu \mathrm{m}^{2} ;$ Chga-KO: $5.56 \pm 0.13 \mu \mathrm{m}^{2}$ ). The ratio between DCVand DC was 47\% higher in Chga-KO mice compared to WT mice (Fig. 2f). While DCV diameter (Fig. 2g; WT: $221.4 \pm 3.66 \mathrm{~nm}$; Chga-KO: $178.93 \pm 3.1 \mathrm{~nm}$ ) was reduced by $\sim 19 \%$ in NE-storing cells, the DC diameter (Fig. 2g; WT: $188.13 \pm 3.5 \mathrm{~nm}$; Chga-KO: $101.32 \pm 1.55 \mathrm{~nm}$ ) was reduced by $\sim 46 \%$ in the NE-storing vesicles of Chga-KO mice compared to WT mice. 


\section{Relative frequency distribution of DCVand DC diameters in Chga-KO mice}

While 250-350 nm DCV diameters predominate in WT NE-storing cells, the preponderant DCV diameters in Chga-KO mice ranged from 100 to $200 \mathrm{~nm}$ (Fig. 2h). Likewise, DC diameters in NE-storing vesicles were higher in WT mice (200-400 nm) compared to ChgaKO mice (50-150 nm) (Fig. 2i).

\section{EPI-storing vesicles in Chga-KO mice show reduced area and diameter}

Like NE cells, the DCV in EPI cells also displayed a dense core (DC: shown by an asterisk in Fig. 3a) and a tiny halo (Fig. 3b, shown by black arrow) in WT mice. Like NE cells, there were three kinds of vesicles: (1) DC and a tiny halo (DCV) (Fig. 3c, d), (2) decreased DC and swelled halo (SDCV, shown by black arrow) (Fig. 3b, d) and (3) swelled halo with no noticeable DC (SEV) (Fig. 3b, d) in Chga-KO mice. In EPI-storing vesicles, although the DCV (Fig. 3e) area was comparable between WT $\left(15.43 \pm 0.38 \mu \mathrm{m}^{2}\right)$ and Chga-KO $\left(15.18 \pm 0.47 \mu \mathrm{m}^{2}\right)$ mice, there was a $\sim 77 \%$ decrease in the DC area (Fig. 3e) in Chga-KO $\left(5.33 \pm 0.11 \mu \mathrm{m}^{2}\right)$ mice compared to WT $\left(10.02 \pm 0.28 \mu \mathrm{m}^{2}\right)$ mice (Fig. 3a-d). Of note, the ratio between DCV and DC was $\sim 33 \%$ higher in Chga-KO mice compared to WT mice (Fig. 3f). The effects of the CgA deficiency were thus less pronounced in EPI-storing vesicles, as there was no change in DCV (Fig. 3g) diameter between WT $(169.46 \pm 2.94 \mathrm{~nm}$ ) and Chga-KO mice (162.69 $\pm 2.59 \mathrm{~nm}$ ). However, DC (Fig. 3g) diameter (WT: 139.97 \pm 2.83 nm; Chga-KO: $98.67 \pm 1.48 \mathrm{~nm}$ ) was reduced by $\sim 30 \%$ in Chga-KO mice compared to WT mice (Fig. 3a-d, g).

\section{Relative frequency distribution of DCVand DC diameters in Chga-KO mice}

EPI cells diameters were comparable between WT and Chga-KO mice except in the 100$200 \mathrm{~nm}$ range groups, where Chga-KO DCVs were preponderant (Fig. 3h). In contrast, DC diameters in the range from 150 to $350 \mathrm{~nm}$ predominated in EPI-storing vesicles in WT mice (Fig. 3i). In Chga-KO mice, the preponderant DC diameter in EPI-storing vesicles was 100 nm (Fig. 3i). Thus, in general, DCVs were smaller in Chga-KO mice.

\section{Effect of insulin challenge (insulin-induced hypoglycemia) on EPI and NE content and DA precursor levels, in adrenal medullae of WTand Chga-KO mice}

In order to determine whether impairment of vesicular granulogenesis as documented in Chga-KO mice (Figs. 1, 2, 3) results in failure to respond to insulin-induced hypoglycemia by both catecholamine release and its repletion consequent to enhanced biosynthesis (Wakade et al. 1988), we measured adrenomedullary NE and EPI content, as well as that of their biosynthetic precursor, DA, both before and after $3 \mathrm{~h}$ of insulin challenge (2 U/kg). As shown in Fig. 4a, b, EPI levels (saline, $1110.7 \pm 20.13$ vs. insulin, $935.47 \pm 40.56 \mathrm{ng} / \mathrm{mg}$ adrenal) are slightly but significantly depleted relative to fasted mice by insulin challenge, whereas NE levels are unaffected, in both Chga-KO and WT mice. DA levels were significantly enhanced in both WT (saline, $23.7 \pm 1.35 \mathrm{vs}$ insulin, $51.55 \pm 3.27 \mathrm{ng} / \mathrm{mg}$ adrenal) and Chga-KO (saline, $19.45 \pm 0.77$ vs $44.05 \pm 3.04 \mathrm{ng} / \mathrm{mg}$ adrenal) mice (Fig. $4 \mathrm{c}$ ). 


\section{Glucose uptake and metabolism}

The level of ${ }^{14} \mathrm{C}-2 \mathrm{DG} 6 \mathrm{P}$ is assumed to represent only glucose uptake (due to lack of further metabolism of this compound) while the level of ${ }^{3} \mathrm{H}-\mathrm{G} 6 \mathrm{P}$ represents glucose uptake as well as utilization. The net utilization of G6P is therefore represented by the difference in the levels of 2DG6P and G6P. We found increased uptake (higher level of 2DG) and utilization of glucose (larger difference in the levels of 2DG6P and G6P) in the adrenal gland from Chga-KO mice compared to WT mice (Fig. 5). Therefore, the difference in their levels (utilization) was higher in Chga-KO mice. In other words, under the condition of cellular stress occasioned by $\mathrm{CgA}$ deficiency, adrenal glucose metabolism was increased in ChgaKO mice.

\section{Mitochondrial lengths, volume and numerical densities and cristae volume density}

Since mitochondrial dysfunction is associated with hypertension (Eirin et al. 2015), we reasoned that Chga-KO mice, by virtue of its hypertensive and hyperadrenergic phenotypes, would affect mitochondrial ultrastructure. Thus, while Chga-KO mice displayed reduced mitochondrial length in NE cells when compared to WT, the length was comparable in EPI cells (Fig. $6 \mathrm{a}-\mathrm{e}$ ). Both the mitochondrial volume and numerical densities in NE and E cells were higher in Chga-KO mice compared to WT mice (Fig. 6f, g). Likewise, Chga-KO mice showed increased cristae volume densities (Fig. 6h).

\section{Rough endoplasmic reticulum (RER) and Golgi complex (GC)}

Since the ER plays crucial roles in mitochondrial function (Arruda et al. 2014; Oakes and Papa 2015) and mitochondrial dysfunction is associated with hypertension (Eirin et al. 2015), we sought to determine whether ER ultrastructure had been altered in Chga-KO mice. We found dilated ER lumen (shown by dashed white line) and increased ribosomal density in Chga-KO mice, indicating increased protein synthesis (Fig. 7a-d).

The Golgi complex (GC) is the site of processing, packaging and sorting of proteins and lipids en route from the ER to the plasma membrane and other destinations (Sengupta and Linstedt 2011). We detected immature secretory granules (ISG: before accumulation of catecholamines) and DCV (after accumulation of catecholamines) adjacent to GC (Fig. 7e, f). Like the ER, the GC also initiates stress signaling to alleviate stress (Jiang et al. 2011). Therefore, we reasoned that hypertension phenotype in Chga-KO mice would alter the ultrastructure of GC. We found dilated GC lumen in Chga-KO mice as compared to WT mice (Fig. 5e-g).

\section{Splanchnic nerve terminal and synaptic vesicles}

Since pre- and postsynaptic sympathetic dysfunctions have been implicated in the pathophysiology of human or animal primary hypertension (de Champlain et al. 1999; Tsuda and Masuyama 1991), we looked at the cholinergic synapses in the adrenal medulla. We found an increased number of mitochondria per unit area (Fig. 8a, b, e) and synaptic vesicles (SV) (Fig. 8c, d, f) per $\mu \mathrm{m}^{2}$ of the synapse (shown by dashed blue line) in Chga-KO chromaffin cells compared to WT mice. In contrast, Chga-KO mice displayed a decreased SV area and diameter (Fig. 8g, h). 


\section{Active zone, exocytosis and endocytosis}

Since vesicle fusion takes place at the active zone, we reasoned that hyperadrenergic ChgaKO would show more vesicles at the active zone (Fernandez-Busnadiego et al. 2013).

Consistent with our hypothesis, we found more vesicles adjacent to the active zone in ChgaKO mice compared to WT mice (Fig. 9a-c). We also found exocytotic and endocytotic vesicles, which are shown by white and blue arrows, respectively (Fig. 9d, e).

\section{Changes in glycogen granules}

At the ultrastructural level, glycogen appears as roughly circular granules from 150 to $400 \AA$ in diameter (Revel et al. 1960). We found an increased number of glycogen granules in Chga-KO mice compared to WT mice (Fig. 9f $-\mathrm{h}$ ).

\section{Discussion}

The accuracy of ultrastructural morphometric analyses to assess cell-specific response in the adrenal gland following Chga-ablation largely depends on the quality of tissue preservation and on the precise identification of NE and EPI cells. The classical paper by Coupland (1965) used $5 \%$ glutaraldehyde in sliced adrenal gland and post-fixation with $1 \% \mathrm{OsO}_{4}$ to differentiate NE and EPI cells. Subsequently, Coupland and colleagues showed that NE and EPI granules can be differentiated quite clearly in tissues fixed in glutaraldehyde only, glutaraldehyde followed by potassium dichromate, iodate or sodium molybdate, as well as glutaraldehyde followed by $\mathrm{OsO}_{4}$ (Coupland and Hopwood 1966). Others and ourselves were unable to distinguish NE and EPI cells using immersion fixation with glutaraldehyde alone or with a mixture of $2.5 \%$ glutaraldehyde and $0.6 \%$ or $5 \%$ paraformaldehyde (Fargali et al. 2014; Grabner and Fox 2006; Kim et al. 2005; Mahapatra et al. 2005). Immersion fixation with $2 \%$ glutaraldehyde and $2 \%$ paraformaldehyde also failed to distinguish NE and EPI cells (Diaz-Vera et al. 2012). Here, we show that perfusion fixation with freshly prepared fixative consisting in a mixture of $2.5 \%$ glutaraldehyde and $2 \%$ paraformaldehyde followed by post-fixation with $1 \% \mathrm{OsO}_{4}$ and en bloc staining with uranyl acetate resulted in clearly distinguishable NE and EPI cells.

The methodology developed here, based on the earlier work of Coupland, allowed us to make quantitative assessments of granule morphology critical for determining the role of $\mathrm{CgA}$ in granulogenesis within the adrenal gland in vivo. A principal observation was the decreased numbers of NE and EPI granules in adrenal medullae of Chga-KO mice, indicating a role of $\mathrm{CgA}$ in granule biogenesis in vivo consistent with preliminary findings in Chga-KO mice in mixed background (Mahapatra et al. 2005); of decreased DCV biogenesis after downregulation of CgA expression in PC12 cells (Kim et al. 2001); and of altered vesicular morphology in a transgenic mouse with $\mathrm{CgA}$ reduced using anti-sense methodology (Kim et al. 2005). Also consistent with our in vivo findings, it has been shown that overexpression of $\mathrm{CgA}$ in fibroblasts resulted in generation of granule-like structures with DCs, which were capable of releasing their contents in a regulated manner (Elias et al. 2012). A previous report suggested that granule biogenesis was not abnormal in Chga-KO mice (Hendy et al. 2006), at odds with cell culture and ex vivo data and with the quantitative in vivo data of the present report. We interpret the results of Hendy et al. (2006) as 
preliminary, given the lack of direct comparison of congenic mice and the use of paraformaldehyde in the absence of glutaraldehyde in their fixative prior to assaying electron microscopical examination of the chromaffin vesicles of the adrenal medulla. The additional possibility exists that on the Balb/CD1 background employed by these workers, the $\mathrm{CgA}$ deficiency phenotype is less penetrant and escaped detection by the methods used. In particular, the work of Hosaka et al. established that secretogranin III may interact with $\mathrm{CgA}$ in mediating granulogenesis in some but not all endocrine secretory cells (Hosaka et al. 2004; Hosaka and Watanabe 2010; Huang et al. 2013). Mouse strain differences could thus account for the differential primacy of chromogranin/secretogranin family members in mediating granulogenesis and this possibility deserves further exploration in order to develop a complete exegesis of the role(s) of chromogranin(s) in endocrine secretory regulation.

For the reasons above, we carefully examined additional cellular parameters in $\mathrm{CgA}$ deficient compared to WT chromaffin cells of the adrenal medulla, as well as catecholamine content of the glands themselves. It appears that NE cells are somewhat more affected by $\mathrm{CgA}$ deficiency as regards preponderance of tubular DCV, DCV area and diameter. Interestingly, increased catecholamine biosynthesis, as reflected in higher levels of adrenomedullary DA, appears to compensate for enhanced catecholamine release during hypoglycemia with respect to NE content but not EPI content and this is apparent in both WT and Chga-KO mice. We interpret these differences as indicating the ability of VMAT reuptake to compensate for loss of efficient storage of both NE and EPI but to do so more fully with respect to NE, which requires only a single round of vesicular VMAT-driven to achieve biosynthesis of NE, compared to EPI, which requires two rounds (first of DA and then of $\mathrm{NE}$ ) of vesicular VMAT transport.

In both NE and EPI cells, we found a substantial number of swelled vesicles with no noticeable DC. In addition, many NE and EPI vesicles were swollen, with a dramatically decreased DC, which resulted in an increased ratio between DCV and DC. It has been suggested by several groups that the vesicle volume is determined by the concentration of soluble core molecules such as catecholamines and ATP (Colliver et al. 2000; Gong et al. 2003). Thus, vesicle swelling may be a consequence of increased intravesicular osmolality secondary to impaired catecholamine complexation and osmotic inactivation. For example, Colliver and colleagues found swelling of vesicles in PC12 cells and in primary chromaffin cells after treatment with L-DOPA, which increased vesicular catecholamine content (Colliver et al. 2000). If binding of $\mathrm{CgA}$ with catecholamines is saturated, then excess catecholamines will be stored outside the DC as free catecholamines. It has been shown that DCVs in hypotonic solution can accumulate water and increase their volume to keep their contents in osmotic equilibrium with their environment (Brodwick et al. 1992; Sudhof 1982). Based on the above findings, Colliver et al. (2000) suggested that increased osmotically active free catecholamines in response to L-DOPA would increase uptake of water, which would result in an increment in vesicle volume.

Since $\mathrm{CgA}$ binds catecholamines with low affinity $\left(\mathrm{K}_{\mathrm{d}}=2.1 \times 10^{-3} \mathrm{M}\right)$ but high capacity (32 mol catecholamines/mol CgA) (Videen et al. 1992) and CgA plays a critical role in forming a binding complex within the vesicle (Berneis et al. 1973; Helle et al. 1985; Kopell and 
Westhead 1982; Mahapatra et al. 2004; Videen et al. 1992; Yoo and Albanesi 1991), we believe that the binding complex in DC is impaired in the absence of $\mathrm{CgA}$, resulting in an increase in osmotically active free catecholamines in the vesicular lumen or halo. Thus, increased concentrations of osmotically active free catecholamines in the lumen resulted in an increase in water uptake and consequent increase in vesicle volume. Consistent with decreased DC, we found 42.5 and $32.9 \%$ decreases in EPI and NE contents, respectively, in the adrenal medulla. This is in agreement with a previous report by Borges's group, studying chromaffin cells from Chga-KO mice ex vivo, which showed $\sim 30 \%$ decrement in vesicular catecholamine content (Montesinos et al. 2008). Our previous report of increased plasma catecholamines in Chga-KO mice (Gayen et al. 2009a; Mahapatra et al. 2005) is in line with the aggregate findings summarized above.

Besides the swelled vesicles with or without a DC, there were many DCVs where the ratio between vesicle and core was comparable in WT and Chga-KO mice. Based on the ultrastructural findings, we hypothesize that the $\mathrm{CgA}$ concentration varies in different vesicles in WT mice and therefore the vesicle sub-populations with the highest CgA levels will be disproportionately affected by $\mathrm{CgA}$ deficiency, i.e., in Chga-KO mice. Vesicles with no noticeable DC thus possibly represent a distinct sub-population that normally contain or require the highest $\mathrm{CgA}$ levels for maintenance of osmotic equilibrium and, therefore, lack of $\mathrm{CgA}$ within this vesicle sub-population leads to complete failure to form the DC storage complex. Osmotically active catecholamines in those vesicles are free in the lumen causing an increase in vesicular uptake of water and consequent increase in vesicular volume. Vesicles with a completely intact dense core in Chga-KO mice, conversely, would be that sub-population in which little $\mathrm{CgA}$ normally exists and in which other members of the chromogranin/secretogranin protein family such as chromogranin B and secretogranin II may serve to facilitate the formation of the DC binding complex of proteins and catecholamines.

Insulin challenge of fasted mice leads to activation of the splanchnic nerve, leading to prolonged catecholamine secretion, which is in fact required for survival during this period of profound hypoglycemia (Hamelink et al. 2002). Increased DA content in response to hypoglycemic stress is consistent with the well-documented increase in tyrosine hydroxlyase enzymatic activity and increased catecholamine biosynthesis elicited by splanchnic nerve stimulation, following hypoglycemia (Sterling and Tank 2001; Thoenen et al. 1969). That these effects were strictly proportional in Chga-KO mice compared to WT mice strongly suggests that the former are able to compensate for impaired granular storage, presumably with enhanced vesicular transport, both during normal sympathoadrenal activation, and even during the period of enhanced catecholamine secretion accompanying prolonged hypoglycemic stress.

Increased glucose uptake in Chga-KO mice may be caused by higher circulating levels of catecholamines in these mice, as it has been shown that catecholamines in the presence of albumin stimulate glucose uptake in muscle. Thus, our findings suggest that glucose uptake in the adrenal gland is regulated similarly to glucose uptake in muscle and in contrast with adipocytes, in which catecholamines have been shown to inhibit glucose uptake (Kirsch et al. 1983; Mulder et al. 2005). However, since a lack of $\mathrm{CgA}$ would be expected to increase 
the osmotic pressure, decrease the storage capacity for catecholamines and increase the energy requirement for maintenance of a sufficient concentration of catecholamines (via VMAT action), increased glucose uptake in the adrenal gland in CgA deficiency fulfills a demand for more energy expenditure needed to keep free catecholamines inside the vesicles. Increased glucose utilization may also provide a stimulus to glycogen storage in Chga-KO mice as seen by ultrastructural studies.

CgA-deficient Chga-KO mice suffer from persistent systemic stress due to increased unregulated secretion of catecholamines and corticosteroids from adrenal glands compared to WT mice, leading to hypertension (Mahapatra et al. 2005). Hypertension is commonly associated with mechanical stretch, increased production of reactive oxygen species (ROS) and fibrosis, eventuating in alteration of the structure and function of subcellular organelles (Eirin et al. 2015). Consistent with the above hypothesis, we found increased mitochondrial numerical and volume densities as well as increased cristae volume density in Chga-KO mice compared to WT mice. We have previously reported increased ROS in Chga-KO mice (Gayen et al. 2010). Others have reported that increased ROS caused dilation of cristae (Noh et al. 2013). Here, we found dilated cristae in Chga-KO mice, which may represent mitochondrial dysfunction resulting in the production of less ATP as has been reported by others in optic nerve head astrocytes (Noh et al. 2013) and by us in the adrenal gland of Chga-KO mice (Mahapatra et al. 2005). In addition to dilated cristae, we found dilated ER lumen in Chga-KO mice, which indicates ER stress (Cheville 2013; Oakes and Papa 2015). The increase in number of ribosomes is indicative of increased protein synthesis and has been reported earlier (Montesinos et al. 2008). Increased protein synthesis demands increased packaging of proteins for regulated secretion (Cheville 2013; Sengupta and Linstedt 2011). Consistent with this hypothesis, we found dilated Golgi lumen, presumably allowing increased packaging of proteins and alleviation of oxidative stress. Furthermore, these results point to the likelihood that processing or clustering of $\mathrm{CgA}$ in the $\mathrm{GC}$, as hypothesized by others (Chanat and Huttner 1991; Kim et al. 2001; Taupenot et al. 2002; Winkler and Fischer-Colbrie 1992), is involved in initial granulogenesis. Thus, the ultrastructural findings of mitochondria, ER and GC fit well the functional impairments reported earlier (Gayen et al. 2009a, 2010; Mahapatra et al. 2005; Montesinos et al. 2008). Overall, it appears that $\mathrm{CgA}$ deficiency in adrenal medulla disrupted the mechanism of maintenance of integrity of catecholamine storage vesicles by increasing osmotic pressure and requiring more energy to keep catecholamines inside the vesicles. This stress permeated across the intracellular vascular system causing dilated ER lumen and mitochondrial cristae.

Increased sympathoadrenal activity plays an important role in the development or maintenance of elevated blood pressure in both hypertensive patients and in animal models of hypertension (Borkowski and Quinn 1985; Goldstein 1983; Westfall and Meldrum 1985). Existing literature reveal that synaptic mitochondria maintain and regulate neurotransmission by buffering $\mathrm{Ca}^{2+}$ (David and Barrett 2003; Medler and Gleason 2002). Congruent with the crucial role played by synaptic mitochondria, it has been reported that removing mitochondria from axon terminals results in aberrant synaptic transmission, which is most likely due to insufficient ATP supply or altered $\mathrm{Ca}^{2+}$ transients (Guo et al. 2005; Ma et al. 2009; Stowers et al. 2002). Thus, the presence of more mitochondria in the Chga-KO synapse compared to WT is indicative of increased neurotransmission, which is further 
supported by the presence of more SV in the Chga-KO synapse coupled with more DCV at the active zone. These ultrastructural findings correlate well with increased plasma catecholamines that we have reported earlier (Mahapatra et al. 2005).

Glycogen, a branched polymer of glucose, is the storage form of carbohydrates in mammals (Philp et al. 2012). Glycogen is used by numerous organisms as a store when glucose is abundant or as a source of glucose under conditions of metabolic depletion (Roach et al. 2012). At the ultrastructural level, glycogen appears as roughly circular granules from 150 to $400 \AA$ in diameter (Revel et al. 1960). One of the main functions of insulin is to stimulate glycogenesis and inhibit glycogenolysis. We have previously reported Chga-KO mice as being hypertensive, hyperadrenergic and sensitive to insulin (Bandyopadhyay et al. 2015; Gayen et al. 2009a, b; Mahapatra et al. 2005). Therefore, increased glycogen granules in the adrenal medulla of Chga-KO mice may be a reflection of heightened insulin sensitivity in Chga-KO mice (Bandyopadhyay et al. 2015; Gayen et al. 2009b).

While lack of $\mathrm{CgA}$ profoundly affects vesicle formation and biogenic amine storage, there is however apparently an equally robust compensation in VMAT-mediated vesicular storage, leading to efficient catecholamine biosynthesis and release in both the resting state and even during greatly enhanced secretory output following induction of hypoglycemia following insulin treatment, in Chga-KO mice. Consistent with an enhanced metabolic burden of ATPdependent vesicular transport in Chga-KO mice, we found evidence for profound alteration in subcellular morphology of organelles involved in energy metabolism, including mitochondria, ER and GC. The ultrastructural findings correlate well with the pathophysiological findings reported earlier in Chga-KO mice (Bandyopadhyay et al. 2015; Gayen et al. 2009a, b; Mahapatra et al. 2005). We also observed greatly enhanced glucose uptake and utilization in Chga-KO mice, consistent with increased metabolic burden on the chromaffin cell in the absence of $\mathrm{CgA}$ expression in the adrenal medulla. We conclude that, in addition to facilitating regulated $\mathrm{CA}$ secretion from the chromaffin cell, $\mathrm{CgA}$ also functions to increase the energy efficiency of VMAT-dependent vesicular catecholamine storage in this endocrine cell.

\section{Acknowledgments}

Transmission Electron Microscopy was conducted at the Cellular \& Molecular Medicine Electron Microscopy Core Facility at UCSD. A Research Career Scientist Award from the Department of Veterans Affairs supports S.K.M. Mahata's personal fund and UCSD Academic Senate Grant (RO091B) supported this work.

\section{Abbreviations}

CA Catecholamines

CgA Chromogranin A protein

Chga Mouse Chromogranin A gene

DA Dopamine

DC Dense core 


$\begin{array}{ll}\text { DCV } & \text { DC vesicle } \\ \text { EPI } & \text { Epinephrine } \\ \text { GC } & \text { Golgi complex } \\ \text { KO } & \text { Knockout } \\ \text { NE } & \text { Norepinephrine } \\ \text { SDCV } & \text { Decreased DC with swelled halo } \\ \text { SEV } & \text { Swelled empty vesicle } \\ \text { SV } & \text { Synaptic vesicle } \\ \text { TEM } & \text { Transmission electron microscopy } \\ \text { VMAT } & \text { Vesicular monoamine transporter } \\ \text { WT } & \text { Wild-type }\end{array}$

\section{References}

Aardal S, Helle KB, Elsayed S, Reed RK, Serck-Hanssen G. Vasostatins, comprising the N-terminal domain of chromogranin A, suppress tension in isolated human blood vessel segments. J Neuroendocrinol. 1993; 5:405-412. [PubMed: 8401564]

Angelone T, Quintieri AM, Brar BK, Limchaiyawat PT, Tota B, Mahata SK, Cerra MC. The antihypertensive chromogranin a peptide catestatin acts as a novel endocrine/paracrine modulator of cardiac inotropism and lusitropism. Endocrinology. 2008; 149:4780-4793. [PubMed: 18535098]

Arruda AP, Pers BM, Parlakgul G, Guney E, Inouye K, Hotamisligil GS. Chronic enrichment of hepatic endoplasmic reticulum-mitochondria contact leads to mitochondrial dysfunction in obesity. Nat Med. 2014; 20:1427-1435. [PubMed: 25419710]

Bandyopadhyay GK, Lu M, Avolio E, Siddiqui JA, Gayen JR, Wollam J, Vu CU, Chi NW, O’Connor DT, Mahata SK. Pancreastatin-dependent inflammatory signaling mediates obesity-induced insulin resistance. Diabetes. 2015; 64:104-116. [PubMed: 25048197]

Bandyopadhyay GK, Vu CU, Gentile S, Lee H, Biswas N, Chi NW, O'Connor DT, Mahata SK. Catestatin (chromogranin A(352-372)) and novel effects on mobilization of fat from adipose tissue through regulation of adrenergic and leptin signaling. J Biol Chem. 2012; 287:23141-23151. [PubMed: 22535963]

Bartolomucci A, Possenti R, Mahata SK, Fischer-Colbrie R, Loh YP, Salton SR. The extended granin family: structure, function, and biomedical implications. Endocr Rev. 2011; 32:755-797. [PubMed: 21862681]

Berneis KH, Goetz U, Da Prada M, Pletscher A. Interaction of aggregated catecholamines and nucleotides with intragranular proteins. Naunyn Schmiedebergs Arch Pharmacol. 1973; 277:291296. [PubMed: 4267257]

Borges R, Diaz-Vera J, Dominguez N, Arnau MR, Machado JD. Chromogranins as regulators of exocytosis. J Neurochem. 2010; 114:335-343. [PubMed: 20456013]

Borkowski KR, Quinn P. Adrenaline and the development of spontaneous hypertension in rats. J Auton Pharmacol. 1985; 5:89-100. [PubMed: 2862149]

Brodwick MS, Curran M, Edwards C. Effects of osmotic stress on mast cell vesicles of the beige mouse. J Membr Biol. 1992; 126:159-169. [PubMed: 1593615]

Chanat E, Huttner WB. Milieu-induced, selective aggregation of regulated secretory proteins in the trans-Golgi network. J Cell Biol. 1991; 115:1505-1519. [PubMed: 1757460] 
Cheville NF. Ultrastructural pathology and interorganelle cross talk in hepatotoxicity. Toxicol Pathol. 2013; 41:210-226. [PubMed: 23344891]

Colliver TL, Pyott SJ, Achalabun M, Ewing AG. VMAT-Mediated changes in quantal size and vesicular volume. J Neurosci. 2000; 20:5276-5282. [PubMed: 10884311]

Coupland RE. Electron microscopic observations on the structure of the rat adrenal medulla: II. Normal innervation. J Anat. 1965; 99:255-272. [PubMed: 17105144]

Coupland RE, Hopwood D. Mechanism of a histochemical reaction differentiating between adrenalineand noradrenaline-storing cells in the electron microscope. Nature. 1966; 209:590-591. [PubMed: 4162279]

Crosson SM, Khan A, Printen J, Pessin JE, Saltiel AR. PTG gene deletion causes impaired glycogen synthesis and developmental insulin resistance. J Clin Invest. 2003; 111:1423-1432. [PubMed: 12727934]

David G, Barrett EF. Mitochondrial Ca2+ uptake prevents desynchronization of quantal release and minimizes depletion during repetitive stimulation of mouse motor nerve terminals. J Physiol. 2003; 548:425-438. [PubMed: 12588898]

de Champlain J, Karas M, Toal C, Nadeau R, Larochelle P. Effects of antihypertensive therapies on the sympathetic nervous system. Can J Cardiol. 1999; 15(Suppl A):8A-14A.

Dev NB, Gayen JR, O'Connor DT, Mahata SK. Chromogranin A and the autonomic system: Decomposition of heart rate variability by time and frequency domains, along with non-linear characteristics during chromogranin A ablation, with "rescue" by its catestatin. Endocrinology. 2010; 151:2760-2768. [PubMed: 20410203]

Diaz-Vera J, Camacho M, Machado JD, Dominguez N, Montesinos MS, Hernandez-Fernaud JR, Lujan $\mathrm{R}$, Borges R. Chromogranins A and B are key proteins in amine accumulation, but the catecholamine secretory pathway is conserved without them. FASEB J. 2012; 26:430-438. [PubMed: 21990378]

Eirin A, Lerman A, Lerman LO. Mitochondria: a pathogenic paradigm in hypertensive renal disease. Hypertension. 2015; 65:264-270. [PubMed: 25403611]

Elias S, Delestre C, Ory S, Marais S, Courel M, Vazquez-Martinez R, Bernard S, Coquet L, Malagon MM, Driouich A, Chan P, Gasman S, Anouar Y, Montero-Hadjadje M. Chromogranin A induces the biogenesis of granules with calcium- and actin-dependent dynamics and exocytosis in constitutively secreting cells. Endocrinology. 2012; 153:4444-4456. [PubMed: 22851679]

Fargali S, Garcia AL, Sadahiro M, Jiang C, Janssen WG, Lin WJ, Cogliani V, Elste A, Mortillo S, Cero C, Veitenheimer B, Graiani G, Pasinetti GM, Mahata SK, Osborn JW, Huntley GW, Phillips GR, Benson DL, Bartolomucci A, Salton SR. The granin VGF promotes genesis of secretory vesicles, and regulates circulating catecholamine levels and blood pressure. FASEB J. 2014; 28:2120-2133. [PubMed: 24497580]

Fernandez-Busnadiego R, Asano S, Oprisoreanu AM, Sakata E, Doengi M, Kochovski Z, Zurner M, Stein V, Schoch S, Baumeister W, Lucic V. Cryo-electron tomography reveals a critical role of RIM 1alpha in synaptic vesicle tethering. J Cell Biol. 2013; 201:725-740. [PubMed: 23712261]

Gayen JR, Gu Y, O’Connor DT, Mahata SK. Global disturbances in autonomic function yield cardiovascular instability and hypertension in the chromogranin A null mouse. Endocrinology. 2009a; 150:5027-5035. [PubMed: 19819970]

Gayen JR, Saberi M, Schenk S, Biswas N, Vaingankar SM, Cheung WW, Najjar SM, O'Connor DT, Bandyopadhyay G, Mahata SK. A novel pathway of insulin sensitivity in chromogranin a null mice: A crucial role for pancreastatin in glucose homeostasis. J Biol Chem. 2009b; 284:2849828509. [PubMed: 19706599]

Gayen JR, Zhang K, Ramachandrarao SP, Mahata M, Chen Y, Kim H-S, Naviaux RK, Sharma K, Mahata SK, O'Connor DT. Role of reactive oxygen species in hyperadrenergic hypertension: Biochemical, physiological, and pharmacological evidence from targeted ablation of the chromogranin A gene. Circ Cardiovasc Genet. 2010; 3:414-425. [PubMed: 20729505]

Goldstein DS. Plasma catecholamines and essential hypertension. An analytical review. Hypertension. 1983; 5:86-99. [PubMed: 6336721] 
Gong LW, Hafez I, Alvarez de Toledo G, Lindau M. Secretory vesicles membrane area is regulated in tandem with quantal size in chromaffin cells. J Neurosci. 2003; 23:7917-7921. [PubMed: 12944522]

Grabner CP, Fox AP. Stimulus-dependent alterations in quantal neurotransmitter release. J Neurophysiol. 2006; 96:3082-3087. [PubMed: 16956996]

Guo X, Macleod GT, Wellington A, Hu F, Panchumarthi S, Schoenfield M, Marin L, Charlton MP, Atwood HL, Zinsmaier KE. The GTPase dMiro is required for axonal transport of mitochondria to Drosophila synapses. Neuron. 2005; 47:379-393. [PubMed: 16055062]

Guo Y, Darshi M, Ma Y, Perkins GA, Shen Z, Haushalter KJ, Saito R, Chen A, Lee YS, Patel HH, Briggs SP, Ellisman MH, Olefsky JM, Taylor SS. Quantitative proteomic and functional analysis of liver mitochondria from high fat diet (HFD) diabetic mice. Mol Cell Proteomics. 2013; 12:3744-3758. [PubMed: 24030101]

Haigh JR, Parris R, Phillips JH. Free concentrations of sodium, potassium and calcium in chromaffin granules. Biochem J. 1989; 259:485-491. [PubMed: 2719661]

Hamelink C, Tjurmina O, Damadzic R, Young WS, Weihe E, Lee HW, Eiden LE. Pituitary adenylate cyclase-activating polypeptide is a sympathoadrenal neurotransmitter involved in catecholamine regulation and glucohomeostasis. Proc Natl Acad Sci U S A. 2002; 99:461-466. [PubMed: 11756684]

Helle KB, Reed RK, Pihl KE, Serck-Hanssen G. Osmotic properties of the chromogranins and relation to osmotic pressure in cate-cholamine storage granules. Acta Physiol Scand. 1985; 123:21-33. [PubMed: 3969832]

Hendy GN, Li T, Girard M, Feldstein RC, Mulay S, Desjardins R, Day R, Karaplis AC, Tremblay ML, Canaff L. Targeted ablation of the chromogranin a (Chga) gene: normal neuroendocrine dense-core secretory granules and increased expression of other granins. Mol Endocrinol. 2006; 20:19351947. [PubMed: 16556729]

Henry JP, Botton D, Sagne C, Isambert MF, Desnos C, Blanchard V, Raisman-Vozari R, Krejci E, Massoulie J, Gasnier B. Biochemistry and molecular biology of the vesicular monoamine transporter from chromaffin granules. J Exp Biol. 1994; 196:251-262. [PubMed: 7823026]

Hosaka M, Suda M, Sakai Y, Izumi T, Watanabe T, Takeuchi T. Secretogranin III binds to cholesterol in the secretory granule membrane as an adapter for chromogranin A. J Biol Chem. 2004; 279:3627-3634. [PubMed: 14597614]

Hosaka M, Watanabe T. Secretogranin III: a bridge between core hormone aggregates and the secretory granule membrane. Endocr J. 2010; 57:275-286. [PubMed: 20203425]

Huang JB, Ding Y, Huang DS, Liang AJ, Zeng WK, Zeng ZP, Qin CQ, Barden B. Inhibition of the $\mathrm{PI} 3 \mathrm{~K} / \mathrm{AKT}$ pathway reduces tumor necrosis factor-alpha production in the cellular response to wear particles in vitro. Artif Organs. 2013; 37:298-307. [PubMed: 23330804]

Iacangelo AL, Eiden LE. Chromogranin A: current status as a precursor for bioactive peptides and a granulogenic/sorting factor in the regulated secretory pathway. Regul Pept. 1995; 58:65-88. [PubMed: 8577930]

Jiang Z, Hu Z, Zeng L, Lu W, Zhang H, Li T, Xiao H. The role of the Golgi apparatus in oxidative stress: is this organelle less significant than mitochondria? Free Radic Biol Med. 2011; 50:907917. [PubMed: 21241794]

Johnson RG Jr. Accumulation of biological amines into chromaffin granules: a model for hormone and neurotransmitter transport. Physiol Rev. 1988; 68:232-307. [PubMed: 2892215]

Kim T, Tao-Cheng J, Eiden LE, Loh YP. Chromogranin A, an "On/Off” Switch Controlling DenseCore Secretory Granule Biogenesis. Cell. 2001; 106:499-509. [PubMed: 11525735]

Kim T, Zhang CF, Sun Z, Wu H, Loh YP. Chromogranin A deficiency in transgenic mice leads to aberrant chromaffin granule biogenesis. J Neurosci. 2005; 25:6958-6961. [PubMed: 16049171]

Kirsch DM, Baumgarten M, Deufel T, Rinninger F, Kemmler W, Haring HU. Catecholamine-induced insulin resistance of glucose transport in isolated rat adipocytes. Biochem J. 1983; 216:737-745. [PubMed: 6667264]

Kopell WN, Westhead EW. Osmotic pressures of solutions of ATP and catecholamines relating to storage in chromaffin granules. J Biol Chem. 1982; 257:5707-5710. [PubMed: 6802820] 
Ma H, Cai Q, Lu W, Sheng ZH, Mochida S. KIF5B motor adaptor syntabulin maintains synaptic transmission in sympathetic neurons. J Neurosci. 2009; 29:13019-13029. [PubMed: 19828815]

Mahapatra NR, Mahata M, Hazra PP, McDonough PM, O'Connor DT, Mahata SK. A dynamic pool of calcium in catecholamine storage vesicles: exploration in living cells by a novel vesicle-targeted chromogranin A/aequorin chimeric photoprotein. J Biol Chem. 2004; 279:51107-51121. [PubMed: 15358782]

Mahapatra NR, O'Connor DT, Vaingankar SM, Hikim AP, Mahata M, Ray S, Staite E, Wu H, Gu Y, Dalton N, Kennedy BP, Ziegler MG, Ross J, Mahata SK. Hypertension from targeted ablation of chromogranin A can be rescued by the human ortholog. J Clin Invest. 2005; 115:1942-1952. [PubMed: 16007257]

Mahata SK, Mahapatra NR, Mahata M, Wang TC, Kennedy BP, Ziegler MG, O’Connor DT. Catecholamine secretory vesicle stimulus-transcription coupling in vivo. Demonstration by a novel transgenic promoter/photoprotein reporter and inhibition of secretion and transcription by the chromogranin A fragment catestatin. J Biol Chem. 2003; 278:32058-32067. [PubMed: 12799369]

Mahata SK, Mahata M, Fung MM, O’Connor DT. Catestatin: a multifunctional peptide from chromogranin A. Regul Pept. 2010; 162:33-43. [PubMed: 20116404]

Mahata SK, O’Connor DT, Mahata M, Yoo SH, Taupenot L, Wu H, Gill BM, Parmer RJ. Novel autocrine feedback control of cate-cholamine release. A discrete chromogranin A fragment is a noncompetitive nicotinic cholinergic antagonist. J Clin Invest. 1997; 100:1623-1633. [PubMed: 9294131]

Medler K, Gleason EL. Mitochondrial Ca(2+) buffering regulates synaptic transmission between retinal amacrine cells. J Neurophysiol. 2002; 87:1426-1439. [PubMed: 11877517]

Montesinos MS, Machado JD, Camacho M, Diaz J, Morales YG, Alvarez de la Rosa D, Carmona E, Castaneyra A, Viveros OH, O'Connor DT, Mahata SK, Borges R. The crucial role of chromogranins in storage and exocytosis revealed using chromaffin cells from chromogranin A null mouse. J Neurosci. 2008; 28:3350-3358. [PubMed: 18367602]

Mulder AH, Tack CJ, Olthaar AJ, Smits P, Sweep FC, Bosch RR. Adrenergic receptor stimulation attenuates insulin-stimulated glucose uptake in 3T3-L1 adipocytes by inhibiting GLUT4 translocation. Am J Physiol Endocrinol Metab. 2005; 289:E627-E633. [PubMed: 15914506]

Noh YH, Kim KY, Shim MS, Choi SH, Choi S, Ellisman MH, Weinreb RN, Perkins GA, Ju WK. Inhibition of oxidative stress by coenzyme Q10 increases mitochondrial mass and improves bioenergetic function in optic nerve head astrocytes. Cell Death Dis. 2013; 4:e820. [PubMed: 24091663]

Oakes SA, Papa FR. The role of endoplasmic reticulum stress in human pathology. Annu Rev Pathol. 2015; 10:173-194. [PubMed: 25387057]

Pacak K, Palkovits M, Yadid G, Kvetnansky R, Kopin IJ, Goldstein DS. Heterogeneous neurochemical responses to different stressors: a test of Selye's doctrine of nonspecificity. Am J Physiol. 1998; 275:R1247-R1255. [PubMed: 9756557]

Patzak A, Winkler H. Exocytotic exposure and recycling of membrane antigens of chromaffin granules: ultrastructural evaluation after immunolabeling. J Cell Biol. 1986; 102:510-515. [PubMed: 3080437]

Philp A, Hargreaves M, Baar K. More than a store: regulatory roles for glycogen in skeletal muscle adaptation to exercise. Am J Physiol Endocrinol Metab. 2012; 302:E1343-E1351. [PubMed: 22395109]

Plattner H, Artalejo AR, Neher E. Ultrastructural organization of bovine chromaffin cell cortexanalysis by cryofixation and morphometry of aspects pertinent to exocytosis. J Cell Biol. 1997; 139:1709-1717. [PubMed: 9412466]

Revel JP, Napolitano L, Fawcett DW. Identification of glycogen in electron micrographs of thin tissue sections. J Biophys Biochem Cytol. 1960; 8:575-589. [PubMed: 13741016]

Roach PJ, Depaoli-Roach AA, Hurley TD, Tagliabracci VS. Glycogen and its metabolism: some new developments and old themes. Biochem J. 2012; 441:763-787. [PubMed: 22248338]

Sanchez-Margalet V, Gonzalez-Yanes C, Najib S, Santos-Alvarez J. Metabolic effects and mechanism of action of the chromogranin A-derived peptide pancreastatin. Regul Pept. 2010; 161:8-14.

[PubMed: 20184923] 
Schuldiner S. A molecular glimpse of vesicular monoamine transporters. J Neurochem. 1994; 62:2067-2078. [PubMed: 7910628]

Sengupta D, Linstedt AD. Control of organelle size: the Golgi complex. Annu Rev Cell Dev Biol. 2011; 27:57-77. [PubMed: 21639798]

Sterling CR, Tank AW. Adrenal tyrosine hydroxylase activity and gene expression are increased by intraventricular administration of nicotine. J Pharmacol Exp Ther. 2001; 296:15-21. [PubMed: 11123357]

Stowers RS, Megeath LJ, Gorska-Andrzejak J, Meinertzhagen IA, Schwarz TL. Axonal transport of mitochondria to synapses depends on milton, a novel Drosophila protein. Neuron. 2002; 36:10631077. [PubMed: 12495622]

Sudhof TC. Core structure, internal osmotic pressure and irreversible structural changes of chromaffin granules during osmometer behaviour. Biochim Biophys Acta. 1982; 684:27-39. [PubMed: 7055554]

Tatemoto K, Efendic S, Mutt V, Makk G, Feistner GJ, Barchas JD. Pancreastatin, a novel pancreatic peptide that inhibits insulin secretion. Nature. 1986; 324:476-478. [PubMed: 3537810]

Taupenot L, Harper KL, Mahapatra NR, Parmer RJ, Mahata SK, O'Connor DT. Identification of a novel sorting determinant for the regulated pathway in the secretory protein chromogranin $\mathrm{A} . \mathrm{J}$ Cell Sci. 2002; 115:4827-4841. [PubMed: 12432071]

Theurl M, Schgoer W, Albrecht K, Jeschke J, Egger M, Beer AG, Vasiljevic D, Rong S, Wolf AM, Bahlmann FH, Patsch JR, Wolf D, Schratzberger P, Mahata SK, Kirchmair R. The neuropeptide catestatin acts as a novel angiogenic cytokine via a basic fibro-blast growth factor-dependent mechanism. Circ Res. 2010; 107:1326-1335. [PubMed: 20930149]

Thoenen H, Mueller RA, Axelrod J. Increased tyrosine hydroxylase activity after drug-induced alteration of sympathetic transmission. Nature. 1969; 221:1264. [PubMed: 4304400]

Tota B, Angelone T, Mazza R, Cerra MC. The chromogranin A-derived vasostatins: new players in the endocrine heart. Curr Med Chem. 2008; 15:1444-1451. [PubMed: 18537621]

Tota B, Gentile S, Pasqua T, Bassino E, Koshimizu H, Cawley NX, Cerra MC, Loh YP, Angelone T. The novel chromogranin A-derived serpinin and pyroglutaminated serpinin peptides are positive cardiac beta-adrenergic-like inotropes. FASEB J. 2012; 26:2888-2898. [PubMed: 22459152]

Tsuda K, Masuyama Y. Presynaptic regulation of neurotransmitter release in hypertension. Clin Exp Pharmacol Physiol. 1991; 18:455-467. [PubMed: 1680586]

Videen JS, Mezger MS, Chang YM, O'Connor DT. Calcium and catecholamine interactions with adrenal chromogranins. Comparison of driving forces in binding and aggregation. J Biol Chem. 1992; 267:3066-3073. [PubMed: 1737762]

Wakade AR, Wakade TD, Malhotra RK. Restoration of catecholamine content of previously depleted adrenal medulla in vitro: importance of synthesis in maintaining the catecholamine stores. $\mathbf{J}$ Neurochem. 1988; 51:820-829. [PubMed: 2900877]

Westfall TC, Meldrum MJ. Alterations in the release of norepinephrine at the vascular neuroeffector junction in hypertension. Annu Rev Pharmacol Toxicol. 1985; 25:621-641. [PubMed: 3890711]

Winkler H, Fischer-Colbrie R. The chromogranins A and B: the first 25 years and future perspectives. Neuroscience. 1992; 49:497-528. [PubMed: 1501763]

Winkler H, Sietzen M, Schober M. The life cycle of catecholamine-storing vesicles. Ann N Y Acad Sci. 1987; 493:3-19. [PubMed: 3296910]

Winkler H, Westhead E. The molecular organization of adrenal chromaffin granules. Neuroscience. 1980; 5:1803-1823. [PubMed: 7432623]

Yoo SH, Albanesi JP. High capacity, low affinity Ca2+ binding of chromogranin A. Relationship between the $\mathrm{pH}$-induced conformational change and Ca2+ binding property. J Biol Chem. 1991; 266:7740-7745. [PubMed: 2019597] 

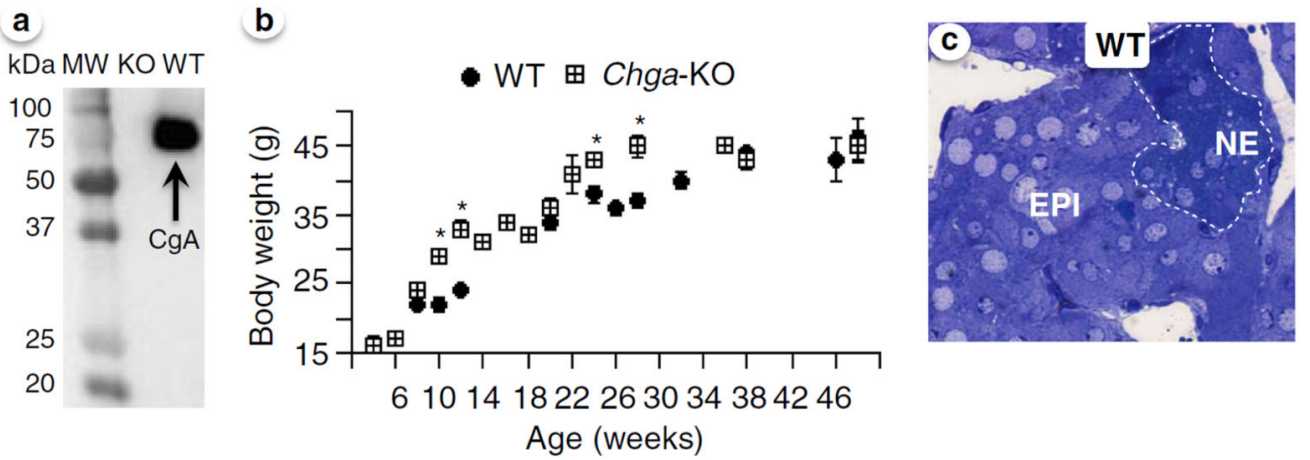

Age (weeks)

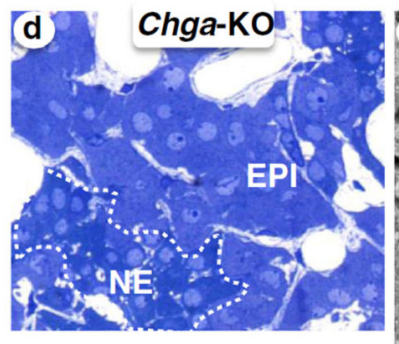

g Volume density

圆 WT ש Chga-KO
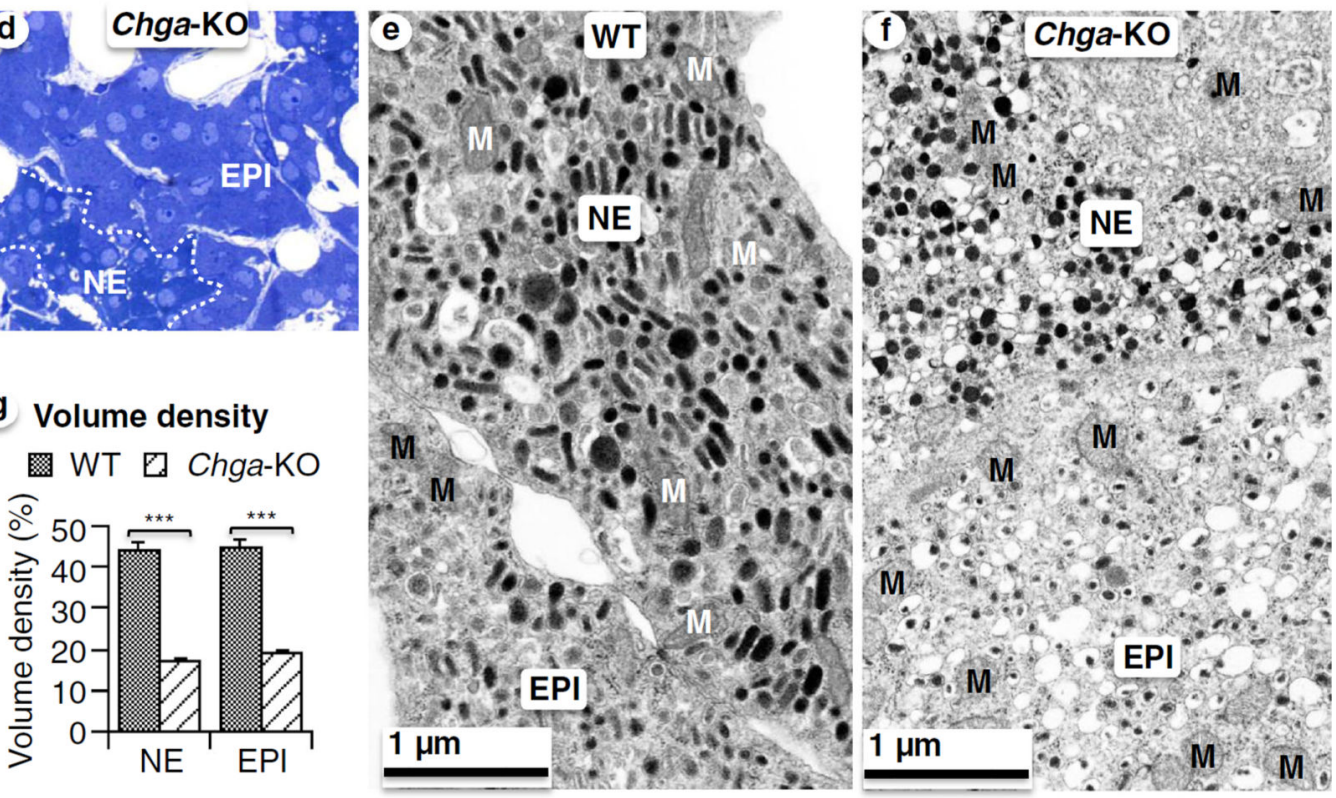

h

Vesicle density

(

Adrenal weight

j Adrenal

WT E Chga-KO

.⿴囗十 $\mathrm{WT}$ ¿ Chga-KO catecholamines
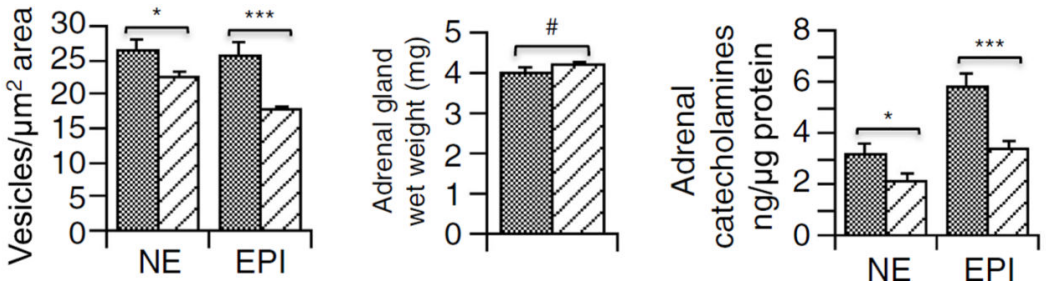

Fig. 1.

a Western blot data with $\mathrm{CgA}$ antibody (human $\mathrm{CgA}_{352-372}$ ) show $\mathrm{CgA}$ band at $\sim 75 \mathrm{kDa}$ in WT mice, which was absent in Chga-KO mice. b Age-dependent changes in body weight in male mice. Each symbol represents the weight of a single animal at that age, while symbols with error bars represent the average weight and range of weights, of multiple animals of the same age. c High-resolution toluidine blue-stained adrenal medulla in WT mice and d ChgaKO mice showing dark blue-stained NE cells (dashed white line boundary) and light bluestained EPI cells. Low-magnification ( $\times 2500$ original magnification) TEM photographs of 
the adrenal medulla. e WT adrenal medulla showing NE and EPI cells. f Chga-KO adrenal medulla showing NE and EPI cells. Morphometric analyses (620 vesicles from 4 mice each of the WT and Chga-KO mice). g Volume densities of chromaffin vesicles in WT and ChgaKO mice. $\mathbf{h}$ Number of chromaffin vesicles per $\mu \mathrm{m}^{2}$ area. $\mathbf{i}$ Weight of the wet adrenal glands $(n=8)$ in WT and Chga-KO mice. j Adrenal catecholamine content (NE and EPI) of WT and Chga-KO adrenal glands ( $n=8)$. KO Chga-KO; $M W$ molecular weight standard; $W T$ wildtype. $* p<0.05 ; * * * p<0.001$ 

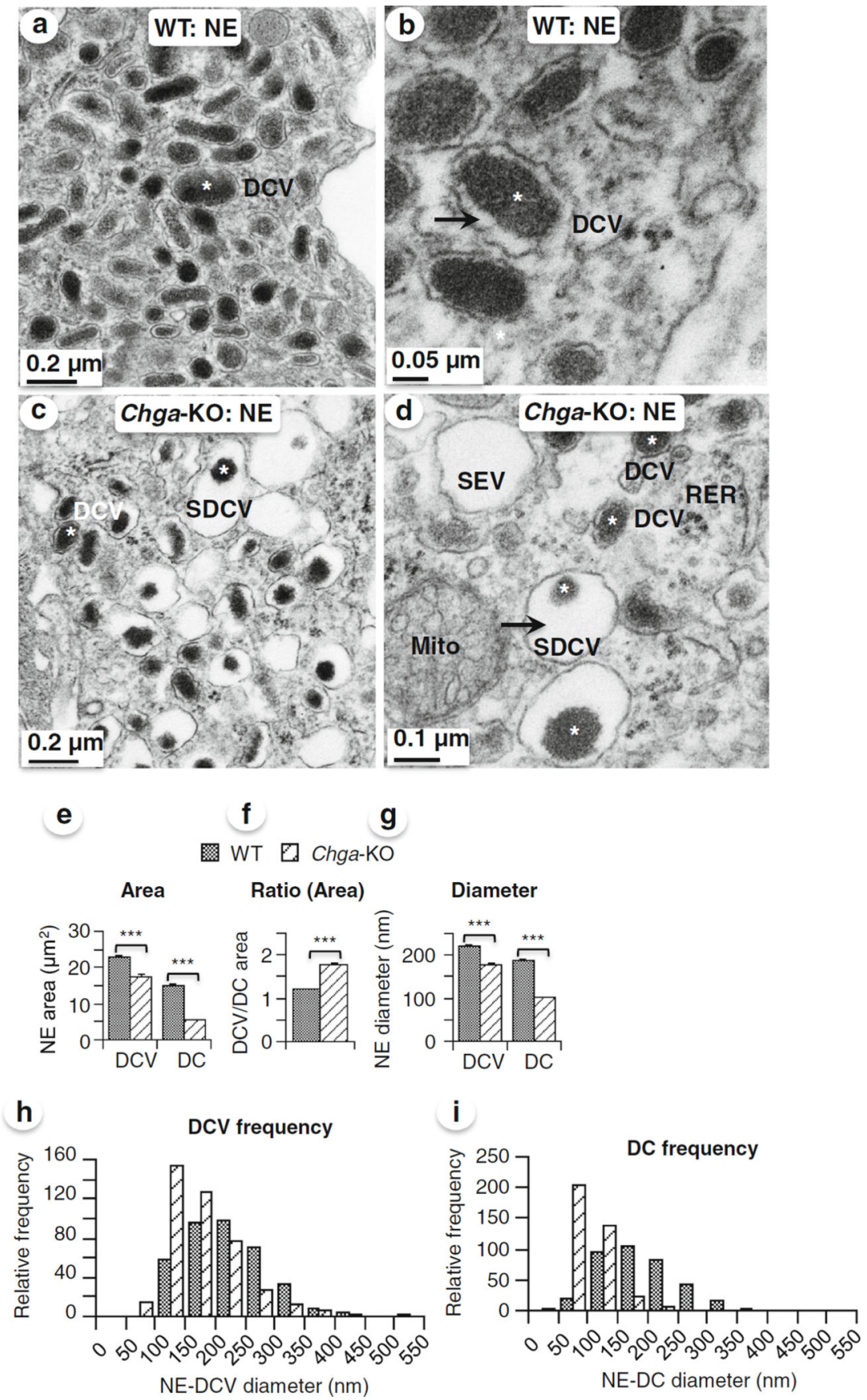

Fig. 2.

Low- ( $\times 5000$ original magnification) and high-magnification $(\times 30,000$ original magnification) TEM photographs of the adrenal medulla. a WT adrenal medulla showing NE cells. b NE vesicles in WT mice. c Chga-KO adrenal medulla showing NE cells. d NE vesicles in Chga-KO mice. Morphometric analyses (620 vesicles from 4 mice each of the WT and Chga-KO mice). e Area of NE vesicle in WT and Chga-KO mice. $\mathbf{f}$ The ratio between NE dense core vesicle and its dense core. $\mathbf{g}$ The diameter of NE vesicle in WT and Chga-KO mice. h Relative frequency distribution of NE vesicle diameters in WT and Chga- 
KO mice. i Relative frequency distribution of NE dense core diameter. Dense core $(D C)$ is shown by asterisks. $D C V$ dense core vesicle; Mito mitochondria; $R E R$ rough endoplasmic reticulum; $S D C V$ swelled DCV; $S E V$ swelled empty vesicle 

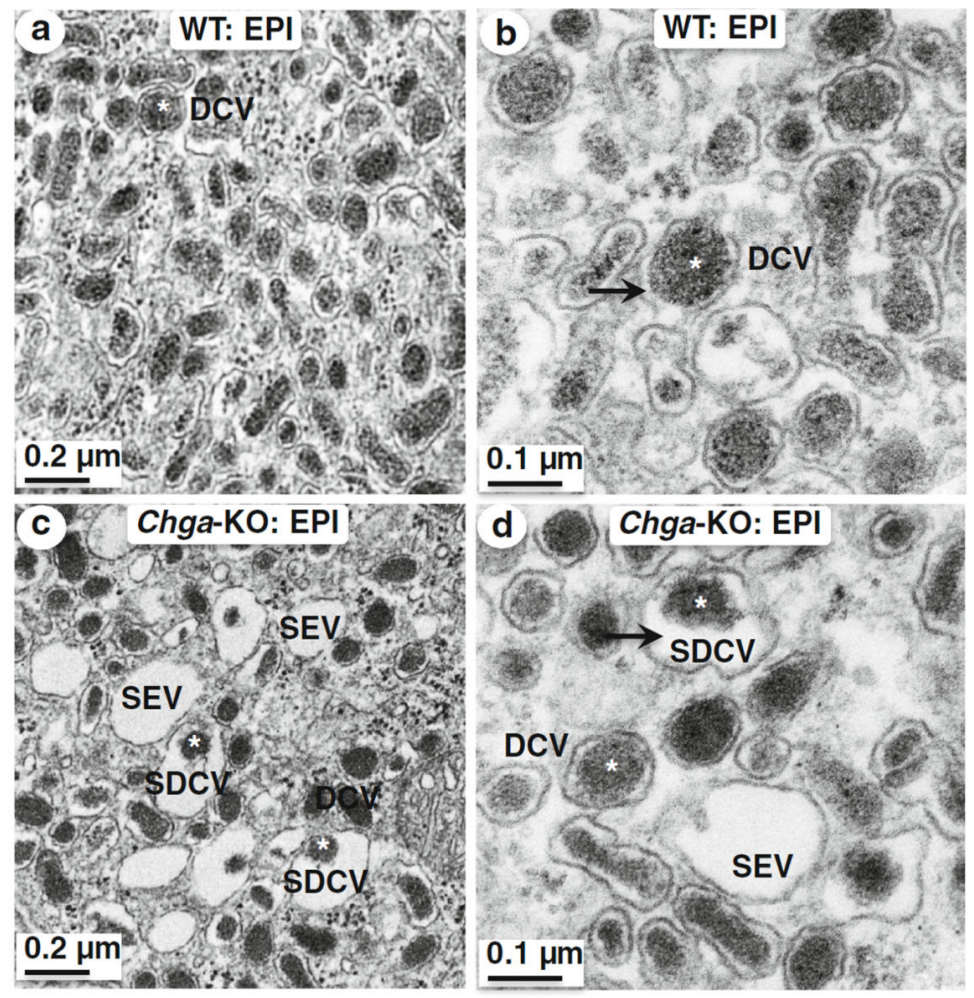

e

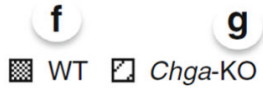

g
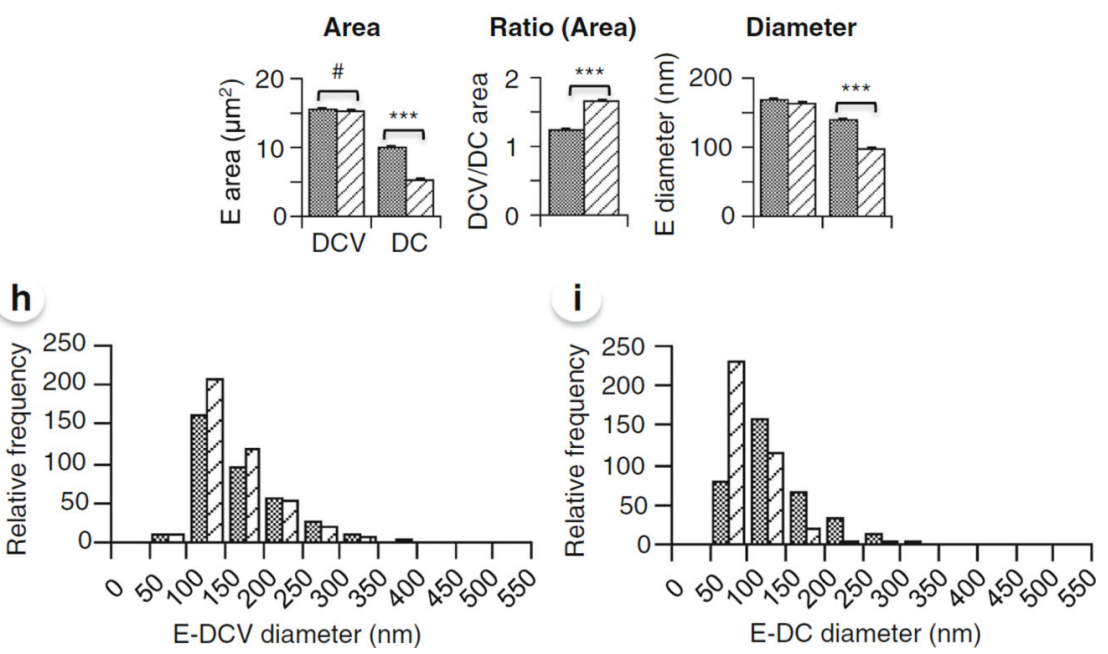

Fig. 3.

Low- ( $\times 5000$ original magnification $)$ and high-magnification $(\times 30,000$ original magnification) TEM photographs of the adrenal medulla. a WT adrenal medulla showing EPI cells. b EPI vesicles in WT mice. c Chga-KO adrenal medulla showing EPI cells. d EPI vesicles in Chga-KO mice. Morphometric analyses (620 vesicles from 4 mice each of the WT and Chga-KO mice). e Area of EPI vesicle in WT and Chga-KO mice. f The ratio between EPI dense core vesicle and its DC. $\mathbf{g}$ The diameter of EPI vesicle in WT and Chga$\mathrm{KO}$ mice. $\mathbf{h}$ Relative frequency distribution of EPI vesicle diameters in WT and Chga-KO 
mice. I Relative frequency distribution of EPI dense core diameter. $D C V$ dense core vesicle; $S D C V$ swelled DCV; $S E V$ swelled empty vesicle 


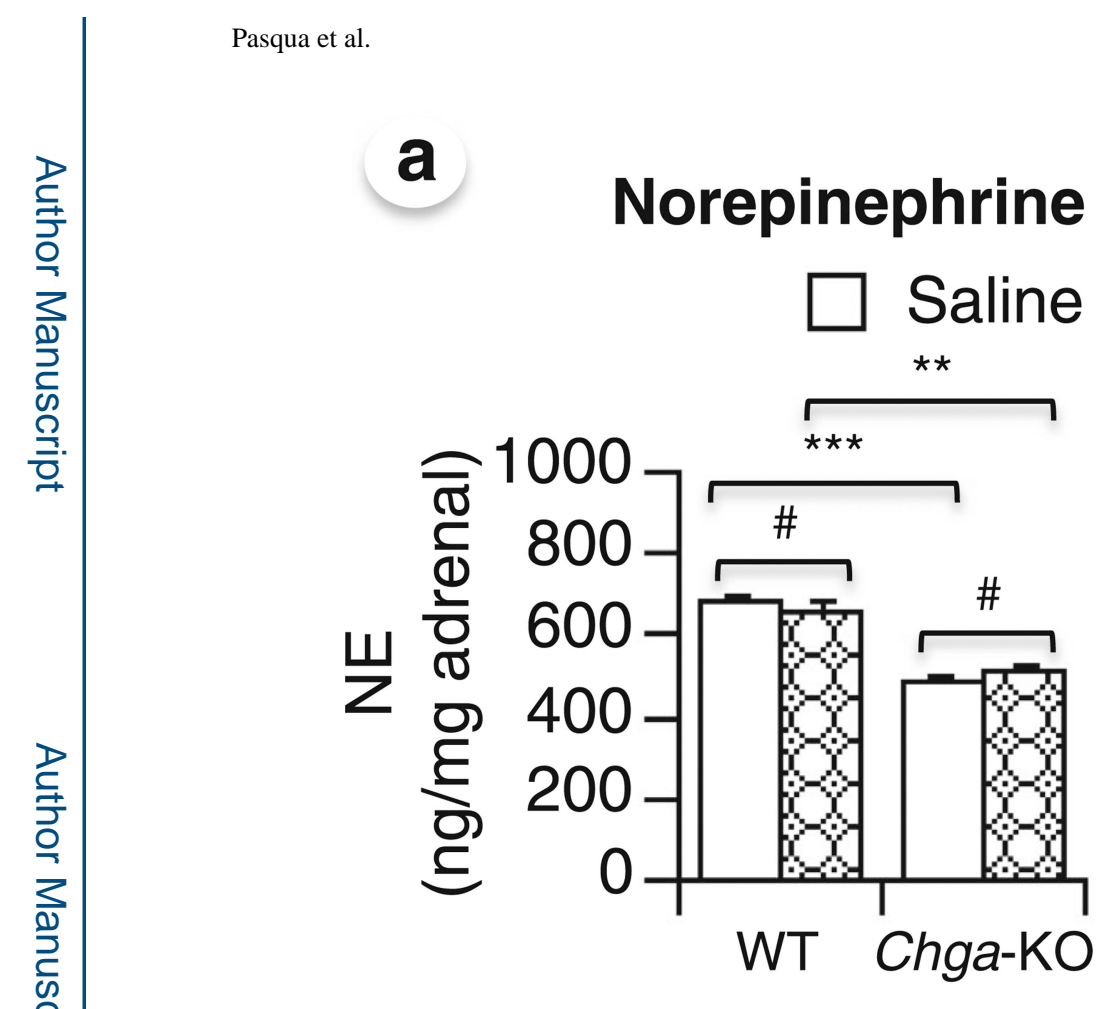

b

Epinephrine
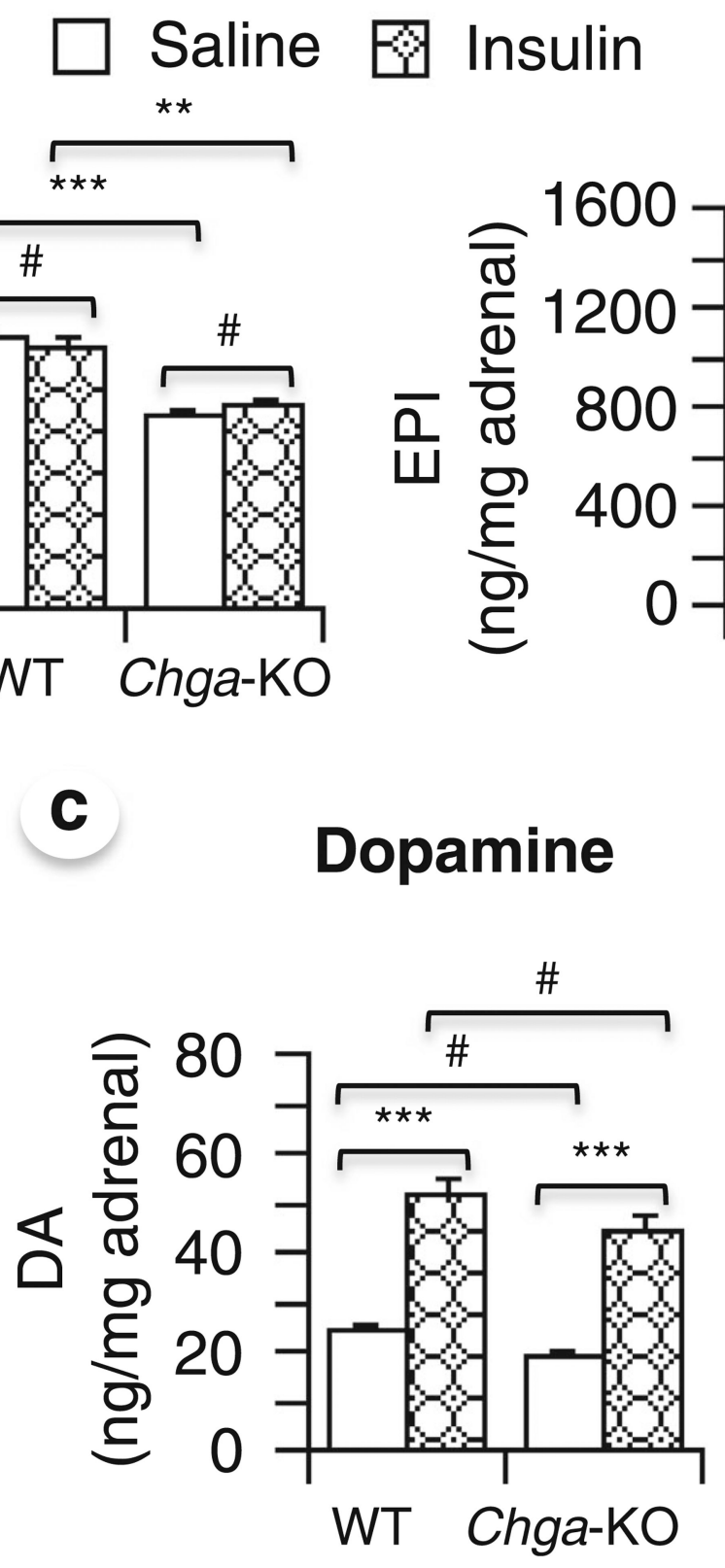

Fig. 4.

Adrenal catecholamine content in both quiescent and hypoglycemic mice. a Norepinephrine.

b Epinephrine. c Dopamine. $* * p<0.01$; $* * * p<0.001$; \# not significant 


\section{Glucose uptake \& utilization}
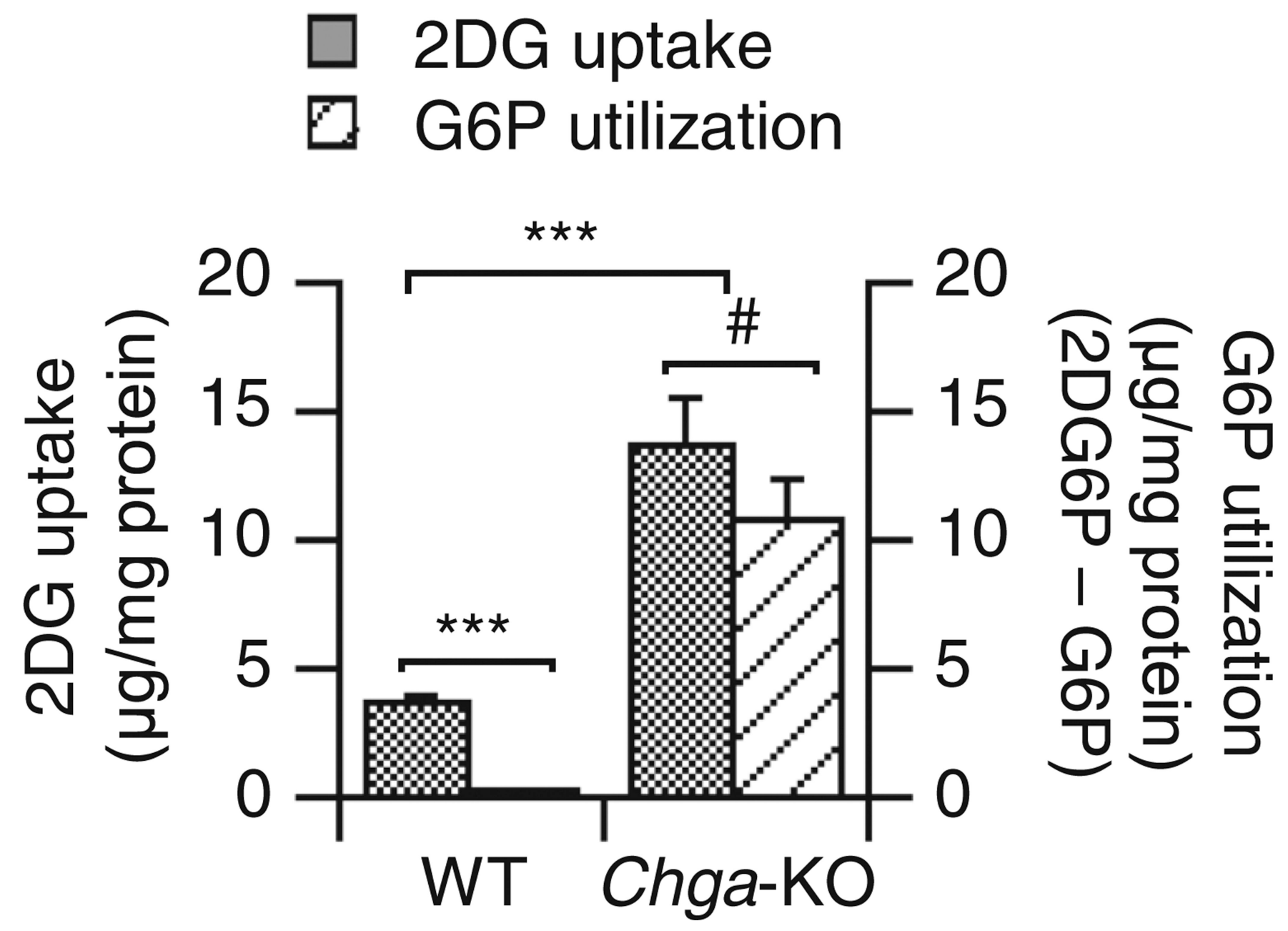

Fig. 5.

Glucose uptake and metabolism in the adrenal gland ( $n=6)$. 2-deoxy-glucose (2DG) uptake and utilization of glucose-6-phosphate (G6P) in overnight fasting mice. $* * p<0.01$;

$* * * p<0.001$; ns not significant 

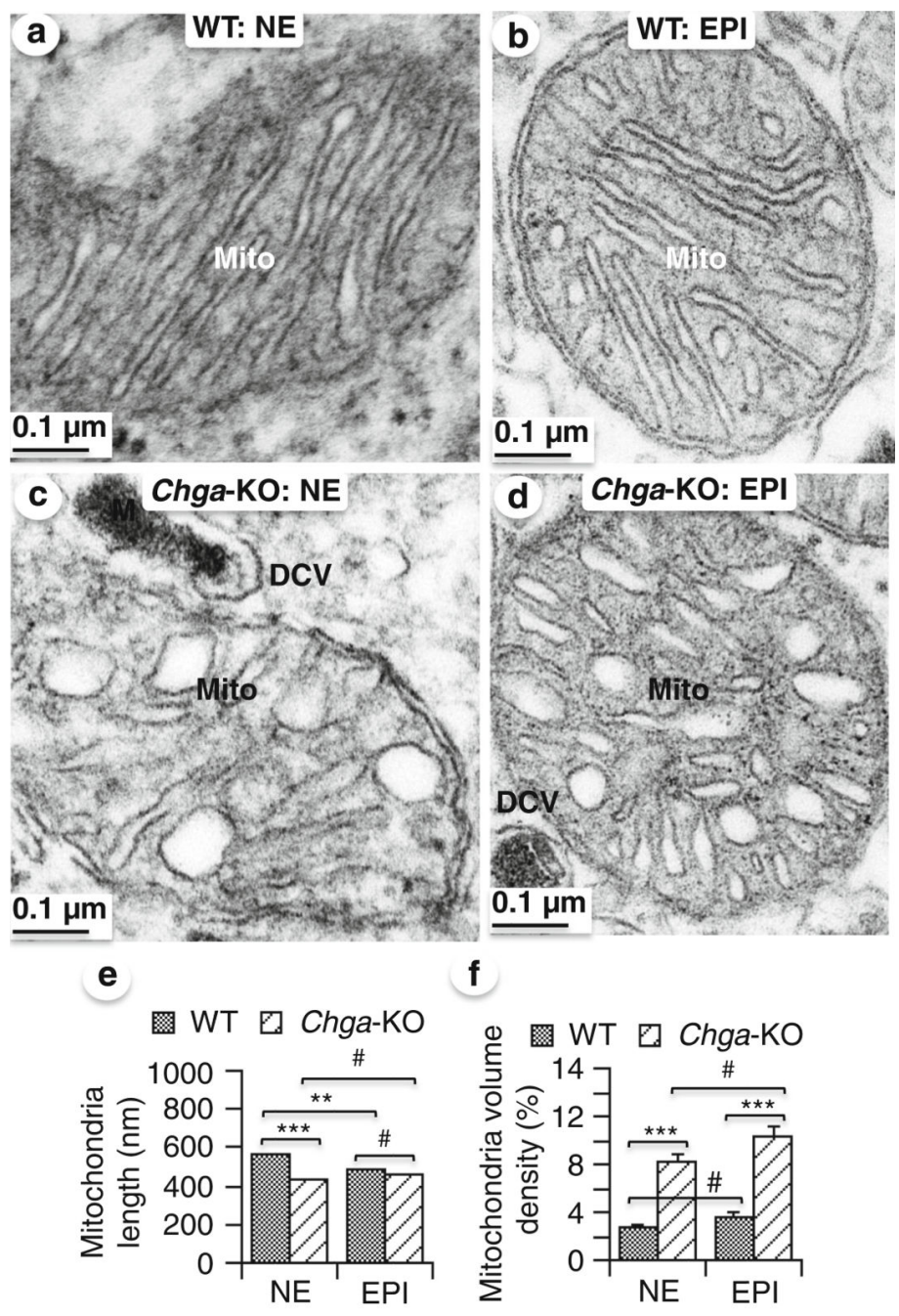

g

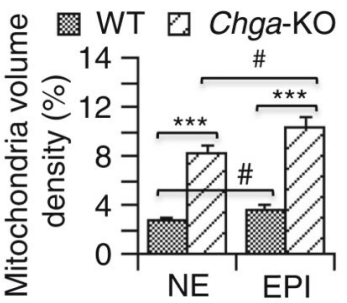

h
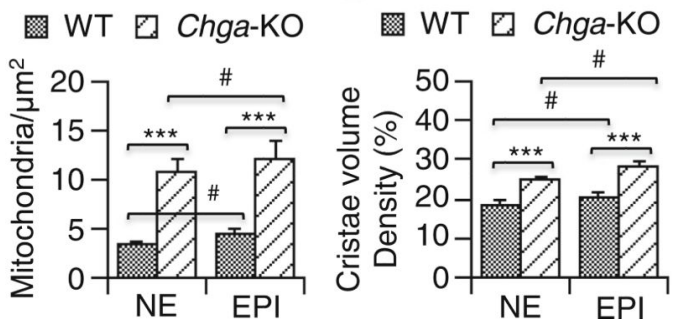

Fig. 6.

High-magnification ( $\times 30,000$ original magnification) TEM photographs of mitochondria. a WT NE cells showing a mitochondrion. b WT EPI cells showing a mitochondrion. $\mathbf{c}$ ChgaKO NE cells showing a mitochondrion. d Chga-KO EPI cells showing a mitochondrion. Morphometric analyses (60 mitochondria from 4 mice each of the WT and Chga-KO mice). e Mitochondrial length. $\mathbf{f}$ Mitochondrial volume density. $\mathbf{g}$ Mitochondria per $\mu \mathrm{m}^{2}$ area of cell. h Cristae volume density. $* * p<0.01 ; * * * p<0.001$; \# not significant 

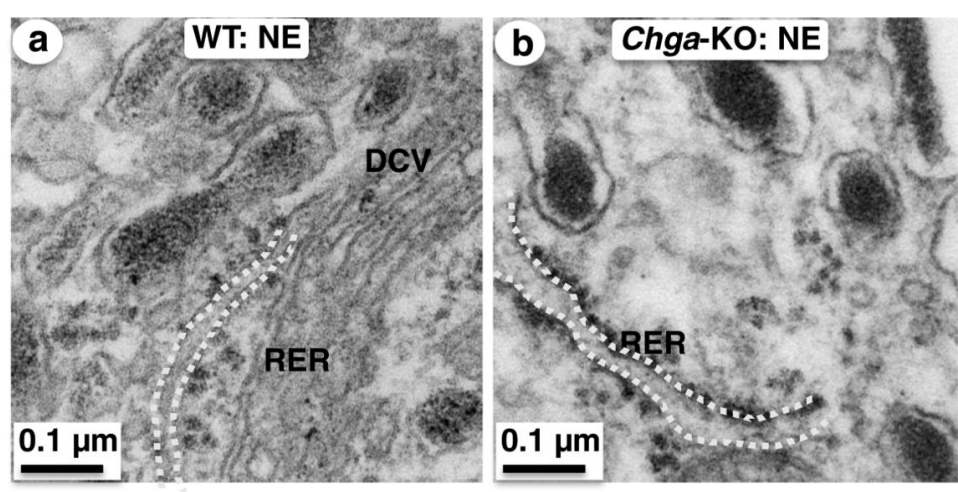

C

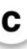

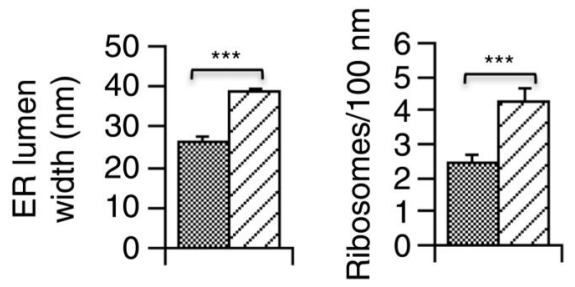
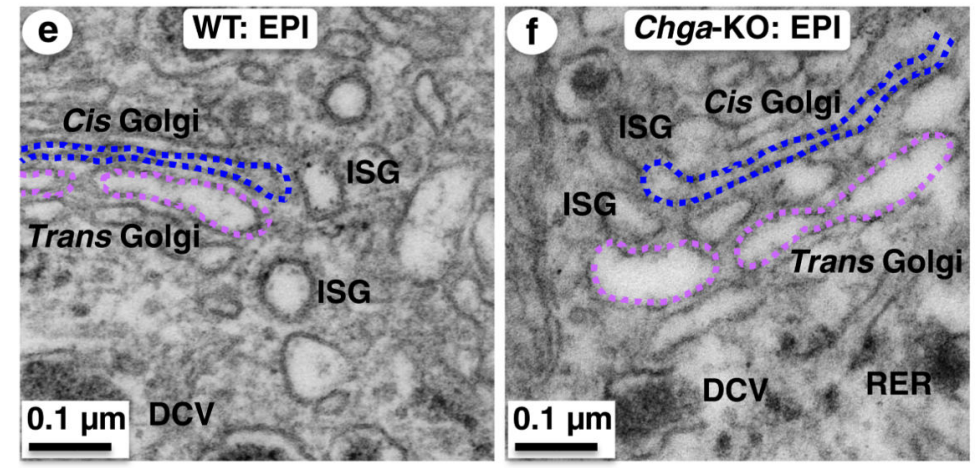

g

圆 WT ש Chga-KO

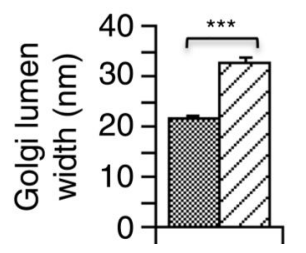

Fig. 7.

High-magnification $(\times 30,000$ original magnification) TEM photographs of rough endoplasmic reticulum (RER) and Golgi complex (GC). a WT NE cells showing a RER. b Chga-KO NE cells showing a dilated RER. c WT E cells showing a GC. d Chga-KO E cells showing a dilated GC. Morphometric analyses (60 RER and GC from 4 mice each of the WT and Chga-KO mice). e ER lumen width. f Ribosomes per $\mu \mathrm{m}^{2}$ area of ER. $\mathbf{g}$ Golgi lumen width. $* * * p<0.001$ 

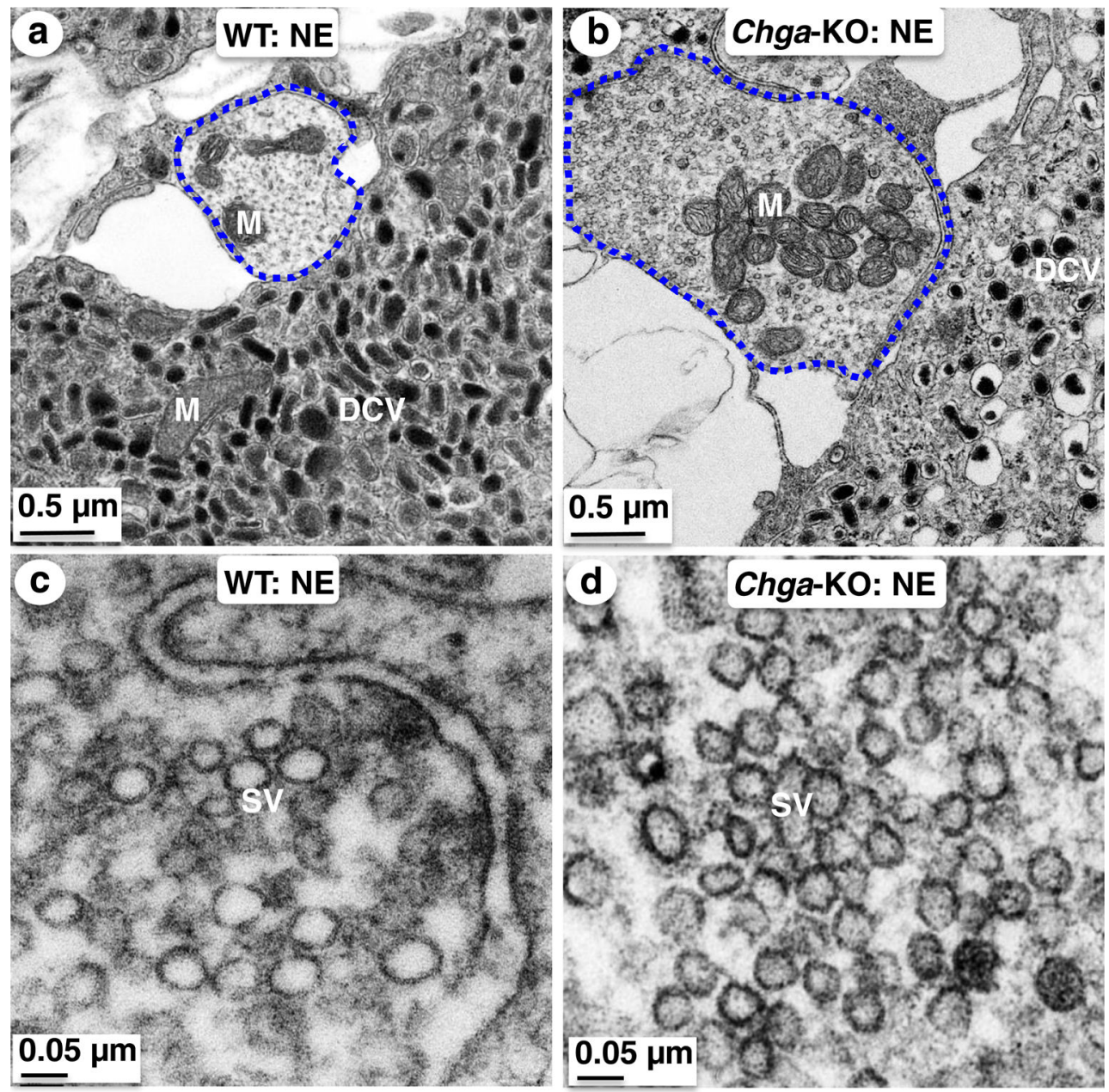

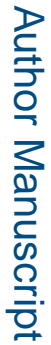
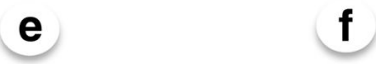

g

h
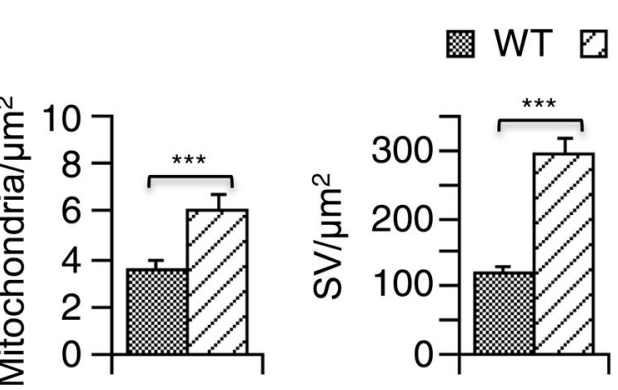

Chga-KO

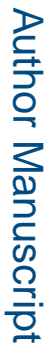

Fig. 8.

Low-magnification ( $\times 5000$ original magnification) TEM photographs of the axon terminal. a Axon terminal in the WT-NE cells. b Axon terminal in the Chga-KO NE cells. Highmagnification $(\times 30,000$ original magnification) TEM photographs of the axon terminal. c WT NE cells showing synaptic vesicle (SV). d Chga-KO NE cells showing SV. Morphometric analyses (20 synapses from 4 mice each of the WT and Chga-KO mice). e Mitochondria per $\mu \mathrm{m}^{2}$ area of the synapse. f SV area $\left(\mu \mathrm{m}^{2}\right)$. g SV diameter (nm). $D C V$ dense core vesicle; $M$ mitochondria; $S V$, synaptic vesicle. $* * * p<0.001$ 


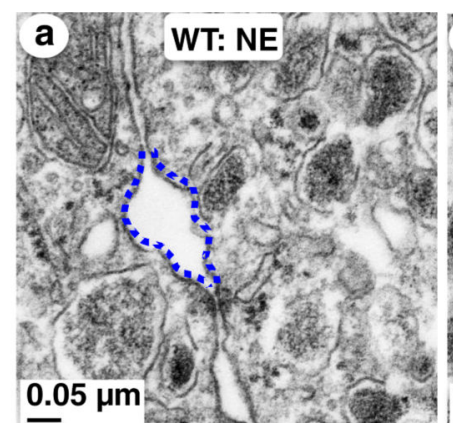

C

Active zone vesicles

冈 WT घ Chga-KO

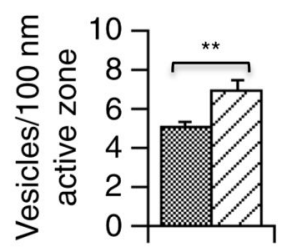

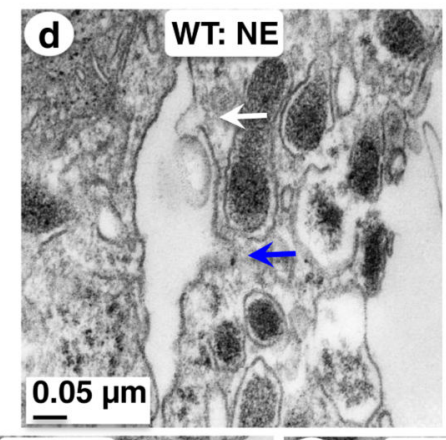
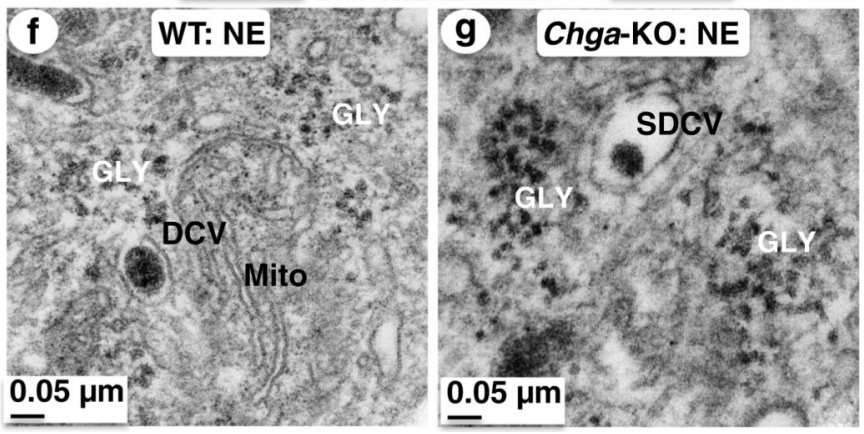

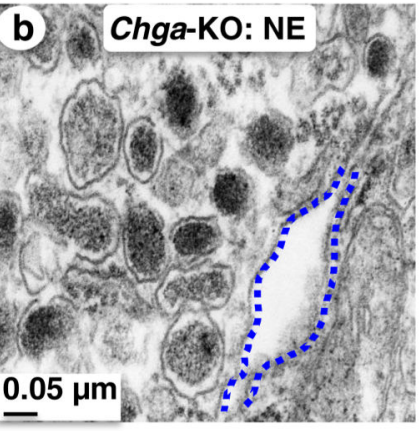

$0.05 \mu \mathrm{m}$

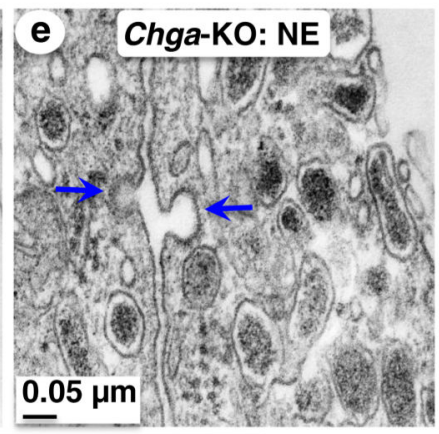

h

Glycogen granules

娄 WT ש Chga-KO

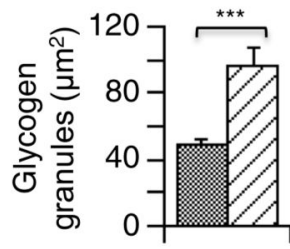

Fig. 9.

High-magnification ( $\times 30,000$ original magnification) TEM photographs of the active zone and glycogen granules. a WT NE cells showing an active zone. b Chga-KO NE cells showing an active zone. c Morphometric data showing number of DCV in $100 \mathrm{~nm}$ of active zone. d WT NE cells showing an exocytotic and an endocytotic vesicle. e Chga-KO NE cells showing endocytotic vesicles. f WT NE cell showing glycogen granules. g Glycogen granules in Chga-KO NE cell. Morphometric analyses (40 cells from 4 mice each of the WT and Chga-KO mice). $\mathbf{h}$ Glycogen granules per $\mu^{2}$ area of cell. Active zone is shown by 
blue broken lines; the white arrow points to an exocytotic vesicle; the blue arrows show endocytotic vesicles. $D C V$ dense core vesicle; $G L Y$ glycogen; Mito mitochondria; $S D C V$ swelled DCV. $* * * p<0.001$ 